\title{
Crippling the bacterial cell wall molecular machinery
}

Allison H. Williams ${ }^{1}$, Richard Wheeler ${ }^{1,2}$, Ala-Eddine Deghmane ${ }^{3}$, Ignacio

Santecchia $^{1,4}$, Francis Impens, ${ }^{6,7,8}$, Paulo André Dias Bastos ${ }^{1,4}$, Samia Hicham ${ }^{1}$, Maryse

Moya Nilges ${ }^{9}$ Christian Malosse $^{10}$, Julia Chamot-Rooke ${ }^{10}$, Ahmed Haouz ${ }^{11}$, William P.

Robins $^{12}$, Muhamed-Kheir Taha ${ }^{3}$, Ivo Gomperts Boneca ${ }^{1}$ *

\section{Affiliations}

${ }^{1}$ Unité Biologie et Génétique de la Paroi Bactérienne, Institut Pasteur; Groupe Avenir, INSERM, 75015 Paris, France

${ }^{2}$ Tumour Immunology and Immunotherapy, Institut Gustave Roussy, F-94805 Villejuif,

France

${ }^{3}$ Unité des Infection Bactériennes Invasives, Institut Pasteur, 75015 Paris, France

${ }^{4}$ Universté Paris Descartes, Sorbonne Paris Cité, Paris, France

${ }^{5}$ Unité des Infections Bactéries-cellules, Institut Pasteur ; Unité 604, INSERM ; Unité sous-contrat 2020, INRA, Paris, 75015, France

${ }^{6}$ Institut Pasteur, Unité des Infections Bactéries-cellules, Paris, 75015, France

${ }^{7}$ Institut National de la Santé et de la Recherche Médicale (INSERM), Unité 604, Paris, 75015, France

${ }^{8}$ Present address: VIB Center for Medical Biotechnology, Department for Biomolecular Medicine, Ghent University, Ghent, Belgium.

${ }^{9}$ Unité Technologie et Service BioImagerie Ultrastructural, Institut Pasteur, 75015, Paris, France

${ }^{10}$ Unité Technologie et Service Spectrométrie de Masse pour la Biologie, Institut Pasteur; UMR 3528, CNRS, 75015 Paris, France

${ }^{11}$ Plate-forme de Cristallographie, Institut Pasteur; UMR3528, CNRS, 75015 Paris, France

${ }^{12}$ Department of Microbiology, Harvard Medical School, Boston, MA, USA. *Correspondence to:

Allison H. Williams, e-mail: awilliam@Pasteur.fr

Ivo G. Boneca, e-mail: bonecai@ Pasteur.fr 


\section{Abstract}

Lytic transglycosylases (LT) are redundant enzymes that play a critical role in

36 peptidoglycan (PG) recycling and metabolism. LT(s) role in cell wall-modifying

37 complexes and usefulness as antimicrobial drug targets remain elusive. We determined at

38 high-resolution a structure of the membrane-bound homolog of the soluble LT from

39 Neisseria species with a disordered active site helix (alpha helix 30). Alpha helix 30 is

40 crucial for binding PG during catalysis ${ }^{1}$. Here we show using an alpha helix 30 deletion

41 strain that LT ( $\operatorname{LtgA})$ determines the integrity of the cell wall, participates in cell division

42 and separation, and can be manipulated to impair the fitness of the human pathogen

43 Neisseria meningitidis during infection. Characterization of $\operatorname{ltg} A$ helix deleted strain

44 interactome identified glycan chain remodeling enzymes whose function appear to be

45 modulated by LTs. Targeting LTs can disrupt the PG machinery, which is fatal for the

46 bacterium, a new approach for antibiotic development. 


\section{Introduction}

Lytic transglycosylases (LTs) degrade peptidoglycan (PG) to produce $\mathrm{N}$ acetylglucosamine (GlcNAc)-1,6-anhydro- $N$-acetylmuramic acid (MurNAc)-peptide (GanhM-peptide), a key cytotoxic elicitor of harmful innate immune responses ${ }^{2}$. LTs have been classified into four distinct families based on sequence similarities and consensus sequences. LTs belonging to family 1 of the glycoside hydrolase (GH) family 23 share sequence similarity with the goose-type lysozyme ${ }^{3}$. Family 1 can be further subdivided into 5 subfamilies, $1 \mathrm{~A}$ through $\mathrm{E}$, which are all structurally distinct ${ }^{3}$. Despite the overall structural differences among LTs, their active sites, enzymatic activities and substrate specificities are fairly well conserved.

The crystal structure of the outer membrane lipoprotein LtgA, a homolog of Slt70 that belongs to family $1 \mathrm{~A}$ of GH family 23 from the pathogenic Neisseria species, was previously determined at a resolution of $1.4 \AA$ (Fig. 1a). ${ }^{4,5}$. Briefly, LtgA is a highly alpha-superhelical structure consisting of 37 alpha helices (Fig. 1a). Although LTs have very diverse overall secondary structures, they exhibit similar substrate specificity and a preference for $\mathrm{PG}^{6}$. LtgA shares an overall weak sequence similarity with Slt70 (25\%). However, the structural and sequence alignments of the catalytic domains of S1t70 and $\operatorname{Ltg} \mathrm{A}$ revealed absolute active site conservation ${ }^{5}$. The active site of $\operatorname{Ltg} \mathrm{A}$ is formed by ten alpha helices $(\alpha 28,29,30,31,32,33,34,35,36,37)$, with a six-alpha-helix bundle ( $\alpha$ $29,30,31,32,33,34)$ constituting the core of the active site that firmly secures the glycan chain (Fig. 1a).

LTs utilize a single catalytic residue, either a glutamate or aspartate, which plays the role of an acid and then that of a base ${ }^{7-11}$. In our recent study, active LtgA was monitored for the first time in the crystalline state, and the residues involved in the substrate and product formation steps were identified. Globally, conformational changes occurred in three domains, the $\mathrm{U}, \mathrm{C}$ and L domains, between native $\mathrm{Ltg} \mathrm{A}$ and $\mathrm{Ltg} \mathrm{A}$ bound to the product ${ }^{5}$. Substantial conformational changes were observed in the active site, for example, during the product formation step, the active site adopted a more open conformation $^{5}$.

Many Gram-negative bacteria have multiple and redundant LTs; for example, Escherichia coli has eight (MltA, MltB, MltC, MltD, MltE, MltF, MltG and Slt70), and 
Neisseria species encodes 5 ( $\operatorname{Ltg} \mathrm{A}, \mathrm{LtgB}, \mathrm{Ltg} C, \mathrm{Ltg} \mathrm{D}$, and $\mathrm{Ltg} \mathrm{E})$, suggesting that $\mathrm{LT}$ activity is vital to the life cycle of the cell ${ }^{12}$. Because the activity of LTs is redundant, the loss of one or more LTs in E. coli leads to no observable growth defects. When genes for 6 LTs were deleted from E. coli, a mild chaining phenotype was observed ${ }^{13}$. However, despite lack of strong observable phenotypic changes, it has been suggested that LTs may have well-defined roles in the cell. For example, the deletion of $\operatorname{ltg} A$ and $\operatorname{ltg} D$ in Neisseria gonorrhoeae eliminates the release of cytotoxic PG monomers suggesting the activity of $\operatorname{Ltg} \mathrm{A}$ and $\operatorname{LtgD}$ are redundant. Moreover, $\operatorname{Ltg} \mathrm{A}$ primarily localizes at the septum, indicating a role in the divisome machinery; whereas, $\operatorname{Ltg} \mathrm{D}$ is distributed along the entire cell surface ${ }^{14}$.

The activities of LTs are known to be inhibited by $\beta$-hexosaminidase inhibitors (for example, NAG-thiazoline); bulgecins A, B and C; and PG- $O$-acetylation ${ }^{4,10,15,16}$. PG$O$-acetylation ${ }^{17}$ is a process that allows pathogenic bacteria to subvert the host innate immune response ${ }^{18,19}$. It should be noted that many Gram-positive and Gramnegative bacteria $O$-acetylate their PG, with a few notable exceptions such as $E$. coli and Pseudomonas aeruginosa ${ }^{20}$. Peptidoglycan $O$-acetylation prevents the normal metabolism and maturation of PG by LTs ${ }^{21}$. Ape1, a PG de $O$-acetylase, is present in Neisseria species and generally in Gram-negative bacteria that $O$-acetylate their PG. Ape 1 catalyzes the hydrolysis of the $O$-acetyl modification specifically at the sixth carbon position of the muramoyl residue, thus assuring the normal metabolism of PG by $\operatorname{LTs}^{17,22,23}$.

LTs are an integral part of the enzymatic PG machinery and forms protein complexes with other members of the PG biosynthetic apparatus, such as PBPs ${ }^{6,12,24-27}$. Most notable are the interactions between S1t70 and PBPs 1b, 1c, 2 and $3^{28}$. PBPs are essential for bacterial cell wall synthesis and are required for proliferation, cell division and the maintenance of the bacterial cell structure. Previously, PBPs were thought to be primarily responsible for the polymerization of PG. Recently, RodA, a key member of the elongasome, and a shape, elongation, division and sporulation (SEDS) protein family member was shown to be a PG polymerase. RodA functions together with PBP2 to replicate the transglycosylase and transpeptidase activities found in bifunctional PBPs ${ }^{29-31}$. SEDS proteins are widely distributed in bacteria and are important in both the cell 
110 elongation and division machinery. Neisseria species such as $N$. gonorrhoeae and N.

111 meningitidis are coccoid in shape and lack an elongation machinery. Therefore, these

112 species incorporate new PG through complex interactions in the divisome. Both $N$.

113 gonorrhoeae and $N$. meningitidis have five PBPs, namely, PBP1, PBP2, PBP3, PBP4 and

114 PBP5. PBP1 and PBP2 are homologous to E. coli PBP1a and PBP3, while the Neisseria

$115 \mathrm{PBP} 3$ and PBP4 are homologous to E. coli PBP4 and PBP7 $7^{32}$. PBP5 in both E. coli and

116 Neisseria species are both predicted carboxypeptidase ${ }^{33}$.

117 FtsW, a RodA homolog and a key component of the divisome machinery, forms a 118 complex with FtsI (PBP3), which has been shown to interact with PBP1b, FtsN and other

119 proteins of the divisome ${ }^{34}$. The FtsW-PBP3 complex shares similar interacting regions

120 with the RodA-PBP2 complex, and is the confirmed PG polymerase of the divisome ${ }^{35}$.

121 Previous work by our group and others have demonstrated that PBPs and LTs can

122 be targeted in a combined antibiotic regimen that could counter antibiotic resistance ${ }^{36}$,

123 highlighting the possibility of simultaneously inhibiting LTs and their binding partners,

124 such as PBPs, to achieve a synergistic antibiotic effect. Here, we reveal the near-atomic-

125 resolution crystal structure of a native version of LtgA with a disordered active site alpha

126 helix. The deletion of LtgA alpha helix 30 affected bacterial growth, disrupted cell

127 division and daughter cell separation, compromised the integrity of the cell wall and PG

128 composition and diminished bacterial fitness or virulence in a mouse infection model. We

129 established the first PG-centric LT interactome study that identified protein partners

130 directly associated with PG assembly (the primary focus of this study) that could be

131 responsible for the observed pleitropic phenotypes. A small hub of glycan strand PG-

132 associated enzymes, that are possibly controlled, functionally regulated, and stabilized by

133 LTs was identified. This study demonstrates that individual LTs, despite their redundancy

134 maybe essential and will likely guide future efforts on how to target LTs for future

135 antibiotic development.

136

137 Results

$138 \quad$ Structure of $\operatorname{Ltg} A$ with a disordered alpha helix 30

140
In the course of monitoring the LtgA reaction in the crystalline state, we captured a native version of $\operatorname{Ltg}$ A with a distinctly disordered alpha helix 30 (Fig. 1b, movie 1). 
141 This represents a newly identified conformational state of $\operatorname{Ltg} \mathrm{A}$ whereby alpha helix 30

142 transitions from an ordered to a disordered state (Fig 1a-b). Interestingly, this disorder of

143 alpha helix 30 did not affect the overall structural integrity of the active site (Fig. 1b,

144 movie 1) because all the other helices making up the catalytic domain remained intact.

145 Moreover, LtgA was already shown to be active in the crystalline state in our previous

146 studies, although the molecular details of alpha helix 30 interactions with the ligand was

147 not addressed (Fig. 1a-b, movie 1$)^{5}$.

148 Alpha helix 30, with the sequence ${ }^{501}$ (MPATAREIAGKIGMD) ${ }^{516}$ (Fig. 1a-b,

149 colored in light red), is structurally conserved among the closest homologs of LtgA,

150 mainly, Slt's, and other LTs such as MltE and MltC ${ }^{8,37-40}$ (Supplementary Fig. 1). Alpha

151 helix 30 clamps the glycan strand during catalysis (Fig. 1c, movie 1) and undergoes

152 conformational changes to a more open conformation after product formation (Fig. 1d).

153 Met 501 and Glu 507 of alpha helix 30 lose hydrogen-bonding contact with the ligand

154 after product formation (Fig. 1d, movie 1). Consistent with the structural data showing

155 the role of alpha helix 30 in substrate/product binding, a heterologously expressed and

156 purified $\operatorname{Ltg}^{\Delta 30}$ showed severely diminished PG binding capabilities when compared to

157 wild-type LtgA or mutants of residues involved in the catalytic mechanism or substrate

158 binding (E481A, E580) of LtgA (Supplementary Fig. 2). This further emphasizes the

159 potential critical structural role of alpha helix 30 in the function of LtgA and

160 consequently in the proper metabolism of the PG. 
a)

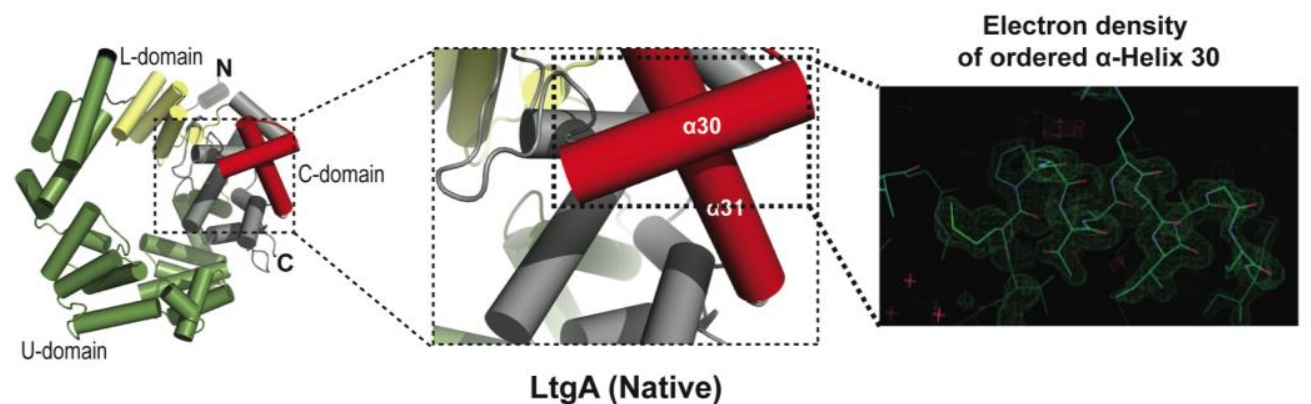

b)

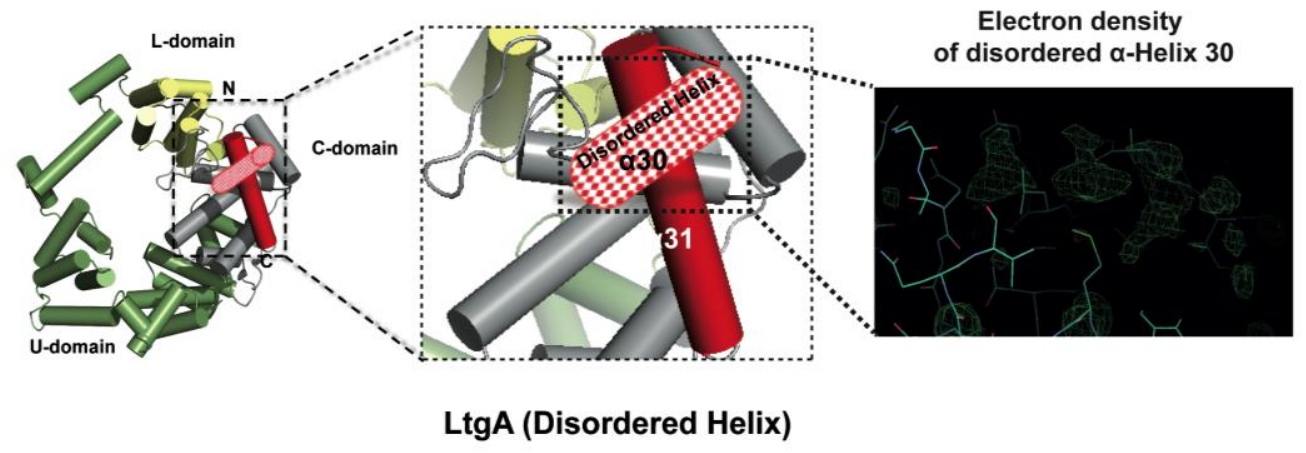

c)

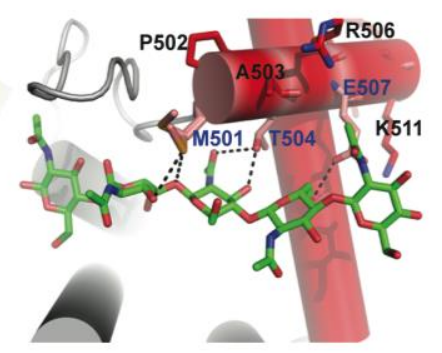

d)

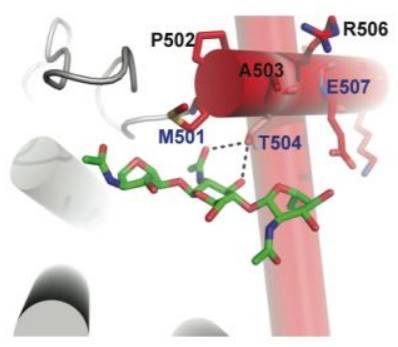

\section{Figure 1. Molecular architecture of $\operatorname{LtgA}$ alpha helix 30 and contacts made with} reaction intermediates.

a) Native structure of LtgA. Ribbon model of LtgA displaying a helical structure consisting of 37 alpha helices. LtgA consists of three domains: A C-domain (gray and red), which houses the putative catalytic domain, and the L (yellow) and U (green) domains, which are of unknown function. A long $\mathrm{N}$-terminal extension interacts with the L-domain, which closes the structure (PDB ID: 5O29). Clear and consistent density for helix 30 was depicted by the Fo-Fc omit map (green) b) LtgA with a disordered conformation of helix 30. Clear and consistent density for helix 30 was absent as depicted by the Fo-Fc omit map (green) of helix 30 (PDB ID: 6H5F). c) LtgA plus trapped intermediates (chitotetraose and a GlcNAc sugar) (PDB ID: 5O2N). d) LtgA plus anhydro product (1,6-anhydro-chitotriose) (PDB ID: 5OIJ). 


\section{The functional role of alpha helix 30}

Given the important structural role of $\operatorname{LtgA}$ alpha helix 30, we investigated its functional role in vivo by engineering the following constructs in N. meningitidis: i) an $\operatorname{Ltg} \mathrm{A}$ knockout strain $(\Delta \operatorname{ltg} A)$, ii) a knockout strain complemented at an ectopic locus on the meningococcal chromosome with the wild-type gene $\left(\Delta \operatorname{ltg} A^{\operatorname{ltg} A}\right)$, or iii) complemented with alpha helix 30 deletion $\left(\Delta \lg A^{\operatorname{ltg} A \triangle 30}\right)$. Similar to other LTs, a complete deletion of the $\operatorname{ltg} A$ gene from the chromosome did not affect the growth of the bacteria (Fig. $2 \mathrm{a})^{41}$. Interestingly, the strain with $\operatorname{ltg} A$ lacking the alpha helix 30 coding sequence exhibited severely reduced growth (Fig. 2a), with an exponential phase growth rate $\left(0.059 \mathrm{~h}^{-1}\right.$ $\pm 0.012)$ significantly different from that of the wild-type or $\Delta \operatorname{ltg} A^{\operatorname{ltg} A}$ strain $\left(0.72 \mathrm{~h}^{-1}\right.$ \pm 0.15 or $0.21 \mathrm{~h}^{-1} \pm 0.043$, respectively) based on the calculated slopes of the growth curves $(p<0.0001)$ (Fig. 2a).

To exclude concerns about $\operatorname{Ltg} \mathrm{A}$ stability and to confirm that $\operatorname{Ltg} \mathrm{A}^{\Delta 30}$ continued to be expressed, the degradation of LtgA across all four strains was examined by western blotting following de novo protein synthesis in the lysates of bacteria harvested at various time points after incubation with chloramphenicol (Fig. 2b-c). The $\Delta \operatorname{ltg} A$ knockout mutant strain did not exhibit any signal (Fig. 2b-c). The level of LtgA in the complemented strains was slightly higher than that in the wild-type strain at $t_{0}$, possibly because the transcription of $\operatorname{ltg} A$ was controlled by a stronger promoter than that in the parental strain. After the addition of chloramphenicol, LtgA appeared to be maintained at comparable levels in the wild-type and complemented strains, and the levels decreased slowly during the sampling period, as revealed by quantitative measurement of relative protein abundance using densitometry $\left(t_{1 / 2}>9 \mathrm{~h}\right)$ (Fig. 2b-c).

The promoter for $\operatorname{ltg} A$ has not yet been identified; therefore, $\operatorname{ltg} A$ was introduced in the chromosome of meningococcus and expressed under the control of a non-native promoter. Since $\Delta \operatorname{ltg} A^{\operatorname{ltg} A \triangle 30}$ exhibited reduced growth and this could be attributed to bacterial lysis or defects in cell division or cell separation, we examined all four strains using fluorescent microscopy (labelling the cell wall and intracellular DNA), and scanning electron microscopy (SEM). Despite the reduced growth of strain $\triangle \operatorname{ltg} A^{\operatorname{ltg} A \triangle 30}$, there was no physical evidence suggesting bacterial lysis. However, intriguingly in the $\Delta \lg A^{\operatorname{ltg} A \Delta 30}$ strain, we observed, strong defects in cell separation and cell division, and the 
206 appearance of membrane stained extracellular material that were notably absent in the

207 other three strains (Fig. 3 (right panel), Supplementary Fig. 3a-b). Additionally, SEM

208 revealed large blebs on the surface of some of unseparated/undivided bacteria in the

$209 \Delta \operatorname{ltg} A^{\operatorname{ltg} A \triangle 30}$ strain that were not observed in the other strains. A rather striking

210 phenomenon is that the bacteria with blebs all had smooth surfaces that deviated from the

211 normal rough surface appearance of N. meningitidis in the other strains (Fig 3 (left panel),

212 Supplementary Fig. 3a-b). We identified ghost cells, however this phenomenon was not

213 as pervasive as other abnormalities (Fig 3 (left panel)). 
a)

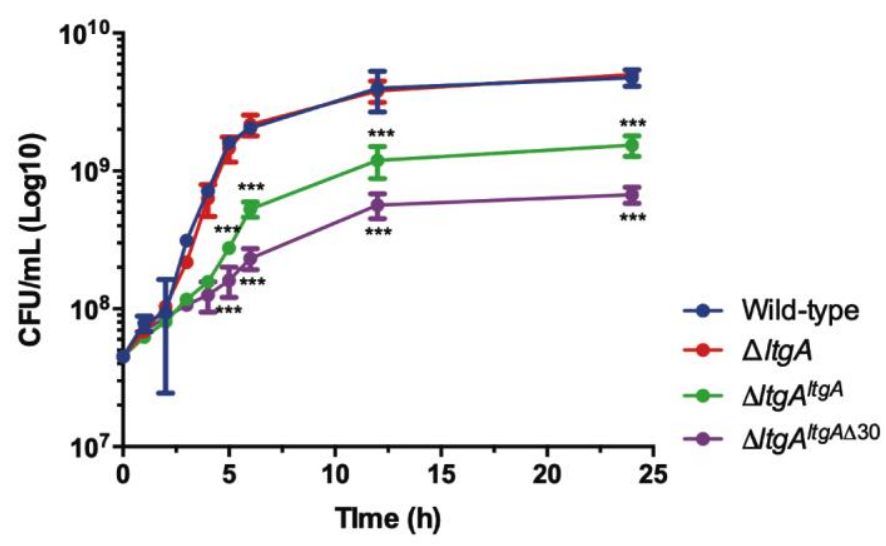

b)
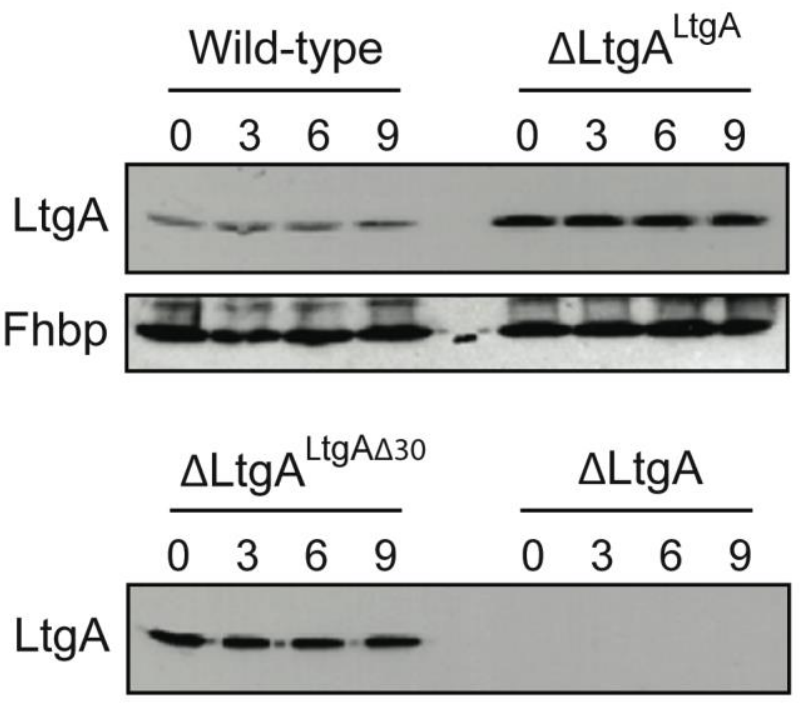

Fhbp

c)

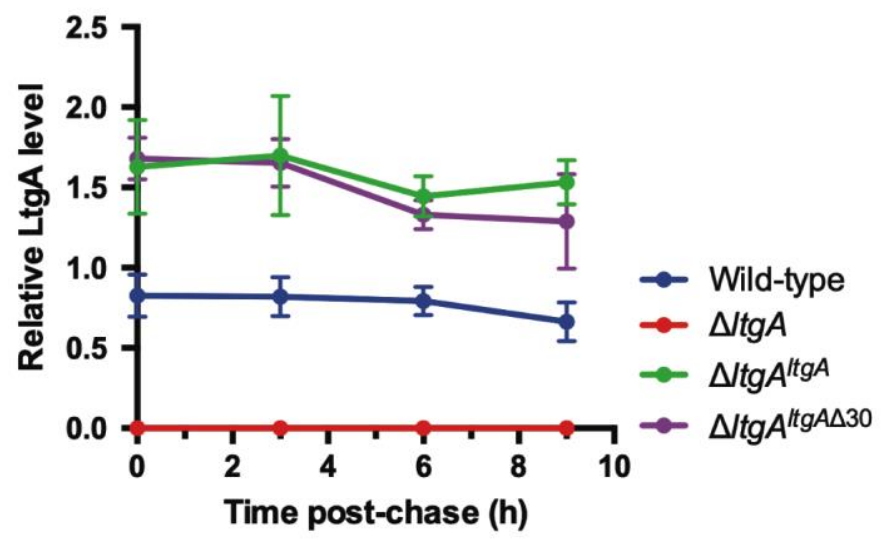




\section{Figure 2. The LtgA helix 30 mutant leads to a growth deffect and is stable}

216 a) Growth kinetics of $N$. meningitidis wild-type, $\Delta \operatorname{ltg} A, \Delta \operatorname{ltg} A^{\operatorname{ltg} A}$ and $\Delta \operatorname{ltg} A^{\operatorname{ltg} A \Delta 30}$. Data

217 represent three independent experiments with $n=3$.

218 b) Exponentially grown bacteria were treated with chloramphenicol $(2 \mu \mathrm{g} / \mathrm{ml})$ to block

219 protein synthesis and survey the stability of LtgA for the indicated periods of time (in

220 hours). Immunoblot was performed probing with anti-LtgA antibody. The expression of

221 the outer membrane protein Fhbp was used as an loading control.

222 c). The levels of LtgA over the time were analysed and ploted as a stability curve by

223 quantifying the band intensities using ImageJ software. For each strain, the $\operatorname{Ltg} \mathrm{A}$

224 intensity at time zero is referred to as $100 \%$, while the simultaneously Fhbp was used for

225 loading control. 
bioRxiv preprint doi: https://doi.org/10.1101/607697; this version posted April 12, 2019. The copyright holder for this preprint (which was not certified by peer review) is the author/funder, who has granted bioRxiv a license to display the preprint in perpetuity. It is made available under aCC-BY 4.0 International license.
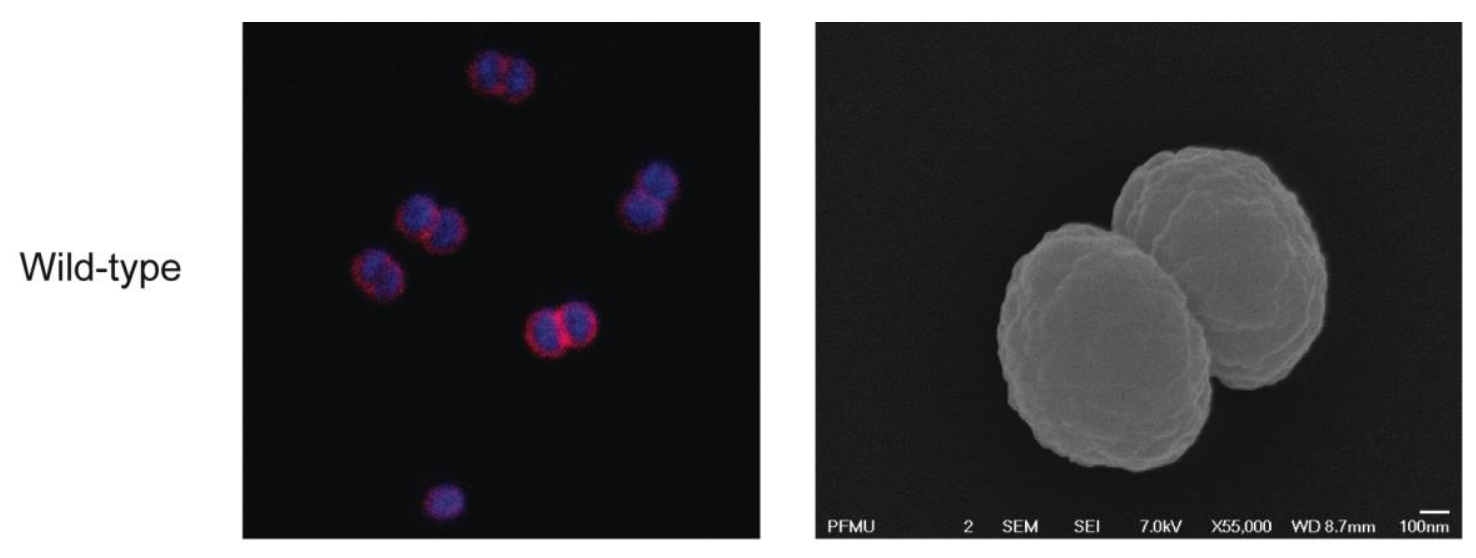

$\Delta \operatorname{tg} A$
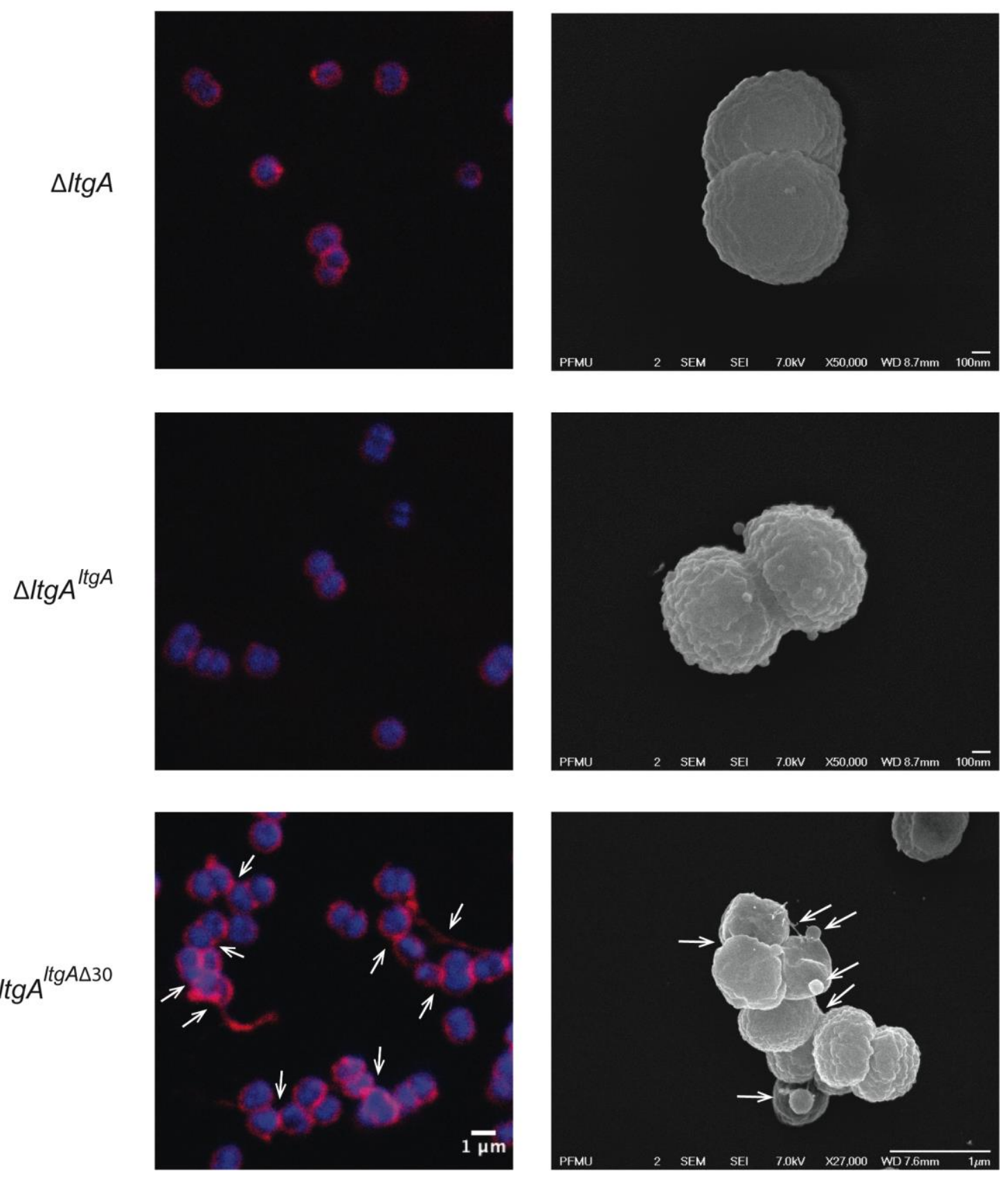
228 Figure 3. The LtgA helix 30 mutant shows morphological abnormalities.

229 Morphological differences between strains of wild type and mutant lytic

230 transglycosylases were determined by fluorescent microscopy (right panel) and scanning

231 electron microscopy (SEM) (left panel). White arrows in the images of $\Delta \operatorname{ltg} A^{\operatorname{ltg} A \Delta 30}$ strain

232 (right panel) points to cells defective in division and separation, as well as extracellular

233 material. White arrows in the left panel points to, irregular cell surfaces, high molecular

234 weight blebs (not observed in other strains), asymmetrical diplococci, and ghost cells.

235 (See Supplementary Fig. 3a-b for other images detailing additional morphological

236 abnormalities)

\section{$L \operatorname{tg} A$ is responsible for maintaining the structural integrity of PG}

We examined the PG profiles of wild-type $N$. meningitidis, $\triangle \operatorname{ltg} A, \Delta \operatorname{ltg} A^{\operatorname{ltg} A}$ and $\Delta \operatorname{ltg} A^{\operatorname{ltg} A \Delta 30}$, to explore whether the integrity of the PG composition of $\Delta \operatorname{ltg} A^{\operatorname{ltg} A \Delta 30}$ strain was maintained. No notable differences were observed among the wild-type, $\triangle \operatorname{ltg} A$ and $\Delta \lg A^{\operatorname{ltg} A}$ strains (Fig. 4, Supplementary Fig. 4, Supplementary table 1). However, the PG of the $\Delta \operatorname{ltg} A^{\operatorname{ltg} A \Delta 30}$ strain was found to be markedly hyperacetylated when compared to that of the other strains, with a $102 \%$ increase in the amount of acetylated GlcNAcanhMurNAc-tetrapeptide (GM*4), a 39\% increase in acetylated GlcNAc-anhMurNActetrapeptide crosslinked with GlcNAc-MurNAc-tetrapeptide (GM*4-GM4), and a 46\%

248 Table 1). A $22 \%$ increase in the amount of GlcNAc-MurNAc tetrapeptide (GM4) was also

249 observed, while the amounts of GlcNAc-MurNAc tripeptide (GM3) and GlcNAc-MurNAc 250 pentapeptide (GM5) decreased by 33\% (Fig. 4, Table 1). Overall, there was a marked increase in the amounts of acetylated PG monomers and dimers. 


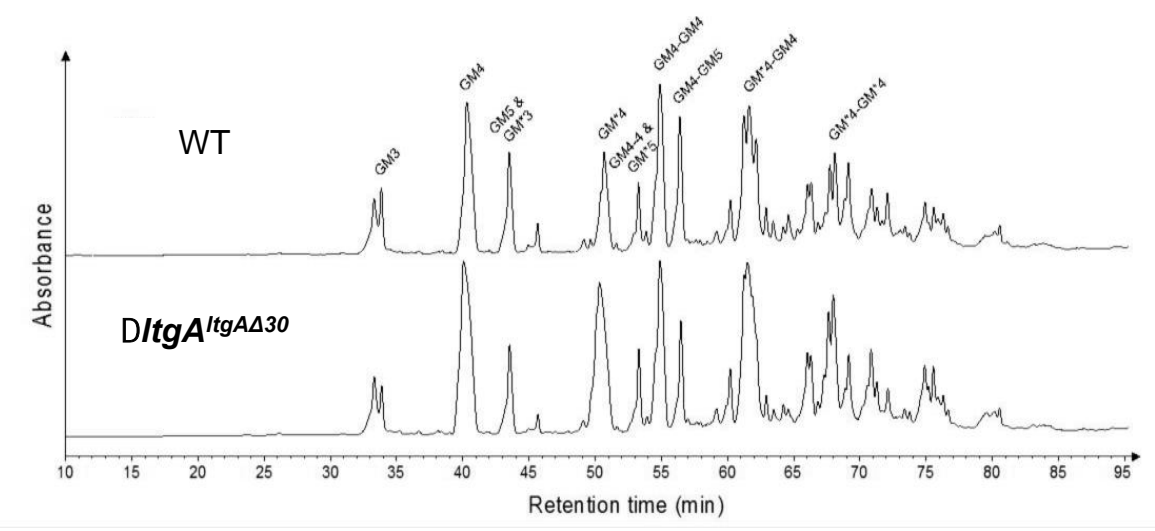

\begin{tabular}{|c|c|c|c|c|c|c|c|c|}
\hline \multirow[t]{2}{*}{ Muropeptide } & \multirow{2}{*}{$\begin{array}{c}\begin{array}{c}\text { Observed } \\
\text { mass }\end{array} \\
\left(\mathrm{m}^{+} \mathrm{H}^{+}\right)\end{array}$} & \multirow{2}{*}{$\begin{array}{c}\text { Theoretical } \\
\text { mass } \\
\left(\mathrm{m}+\mathrm{H}^{+}\right)\end{array}$} & \multicolumn{4}{|c|}{$\begin{array}{l}\text { Proportion of total } \\
\text { muropeptides (\%) }\end{array}$} & \multirow{2}{*}{$\begin{array}{l}\text { Fold-change } \\
\text { WT /Helix30 }\end{array}$} & \multirow{2}{*}{$\begin{array}{c}\begin{array}{c}\text { Fold- } \\
\text { change (\%) }\end{array} \\
\text { WT /Helix30 }\end{array}$} \\
\hline & & & WT & (SD) & Helix30 & (SD) & & \\
\hline GM3 & 871.38 & 871.38 & 2.34 & $( \pm 0.19)$ & 1.56 & $( \pm 0.16)$ & 0.67 & $33 \downarrow$ \\
\hline GM4 & 942.41 & 942.42 & 11.14 & $( \pm 0.33)$ & 13.60 & $( \pm 0.47)$ & 1.22 & $22 \uparrow$ \\
\hline $\begin{array}{l}\text { GM5 } \\
\text { GM*3 }\end{array}$ & $\begin{array}{r}1013.45 \\
913.39\end{array}$ & $\begin{array}{r}1013.45 \\
913.39\end{array}$ & 4.82 & $( \pm 0.05)$ & \multicolumn{2}{|c|}{$3.45( \pm 0.10)$} & 0.72 & $28 \downarrow$ \\
\hline $\mathrm{GM}^{*} 4$ & 984.42 & 984.43 & 4.41 & $( \pm 0.45)$ & 8.89 & $( \pm 0.37)$ & 2.02 & $102 \uparrow$ \\
\hline $\begin{array}{l}\text { GM4-4 } \\
\text { GM*5 }\end{array}$ & $\begin{array}{l}1385.61 \\
1055.46\end{array}$ & $\begin{array}{l}1385.62 \\
1055.64\end{array}$ & 2.98 & $( \pm 0.12)$ & \multicolumn{2}{|c|}{$2.96( \pm 0.12)$} & 0.99 & $1 \downarrow$ \\
\hline GM4-GM4 & 1865.80 & 1865.81 & 10.56 & $( \pm 0.50)$ & 9.54 & $( \pm 0.42)$ & 0.90 & $10 \downarrow$ \\
\hline GM4-GM5 & 1936.84 & 1936.85 & 6.25 & $( \pm 0.08)$ & 3.96 & $( \pm 0.09)$ & 0.63 & $37 \downarrow$ \\
\hline $\mathrm{GM}^{*} 4-\mathrm{GM} 4$ & 1907.86 & 1907.82 & 6.73 & $( \pm 0.59)$ & 9.35 & $( \pm 0.23)$ & 1.39 & $39 \uparrow$ \\
\hline $\mathrm{GM}^{*} 4-\mathrm{GM}^{*} 4$ & 1949.83 & 1949.83 & 3.24 & $( \pm 0.37)$ & 4.73 & $( \pm 0.21)$ & 1.46 & $46 \uparrow$ \\
\hline
\end{tabular}

\section{Figure 4. Muropeptide composition of PG isolated from wild-type and $\triangle \operatorname{ltg} A^{\operatorname{ltg} A 430}$.}

Purified PG was digested by muramidase mutanolysin, and the resulting muropeptides were reduced and then analyzed by LC/MS. The results were reproducible over 4 biological replicates. Peak identifications correspond to Table 1.

Table 1. Muropeptides identified by mass spectrometry.* indicates O-acetylated MurNAc. Acetylated $\mathrm{GM}^{*} 4$ is highlighted in bold. Multiple muropeptides coeluted as a single peak are shaded in pink. Red arrows indicate a decrease and blue arrows an increase in muropeptide abundance. The table displays the observed and theoretical masses and the proportion of total muropeptides. 


\section{The protein-protein interactome of LtgA reveals binding partners involved in the $P G$}

\section{machinery}

To date, there have been no PG-centered omic studies on enzymes involved in cell wall biosynthesis. Deletion of the LtgA alpha helix 30 had a multifactoral impact on Neisseria, including impaired growth, defects in cell division or cell separation, and altered PG composition. Therefore, we decided to explore whether impaired LtgA activity could perturb the protein molecular environment of PG assembly.

To identify partners of LtgA potentially involved in PG and cell wall metabolism we utilized coimmunoprecipitation followed by high-performance affinity enrichment mass spectrometry using $\Delta \operatorname{ltg} A, \Delta \operatorname{ltg} A^{\operatorname{ltg} A}$ and $\Delta \operatorname{ltg} A^{\operatorname{ltg} A \Delta 30}$ strains (Fig. 5a-b). These coimmunoprecipitation experiments were performed with each strain in triplicate (Fig. 5a-b). To our knowledge, this experiment is the first large-scale assessment of the protein-protein interactions of LTs. We then created a protein-protein interactome (PPI) network and, carried out a Clusters of Orthologous Groups (COG) analysis to classify the proteins identified in the PPI network for the $\Delta \operatorname{ltg} A^{\operatorname{ltg} A \Delta 30}$ strain (Supplementary Fig. 5). We discovered that the proteins identified in this network belong to 2 main functional categories: i) cell wall/membrane/envelope biogenesis and ii) intracellular trafficking, secretion, and vesicular transport (Supplementary Fig. 5). Intriguingly, the interactors of $\operatorname{Ltg} \mathrm{A}^{\Delta 30}$ identified in the $\Delta \operatorname{ltg} A^{\operatorname{ltg} A \Delta 30}$ mutant strain showed enrichment of peptides from known members of the PG synthesis machinery, that along with LtgA utilize the PG glycan strand as substrate (PBP1a, and the E. coli MltD homolog LtgE and LtgD a homolog of E. coli MltB) (Fig. 5,a-b, Supplementary table 2).

As expected, $\operatorname{Ltg} \mathrm{A}$ was found to be significantly enriched in the $\Delta \operatorname{ltg} A^{\operatorname{ltg} A}$ strain compared with the $\Delta \operatorname{ltg} A$ strain. No other enzymes directly involved in PG assembly were enriched in the $\Delta \operatorname{ltg} A^{\operatorname{ltg} A}$ strain, however, FtsN an essential divisome protein, previously shown to activate septal PG synthesis and constriction of the cell was enriched (Fig. 5a-b, Supplementary table 2). In contrast, the deletion of a single alpha helix led to an enrichment of enzymes known to be involved in PG synthesis (PBP1a, LtgE and LtgD) (Fig. 5a-b, Supplementary table 2). 


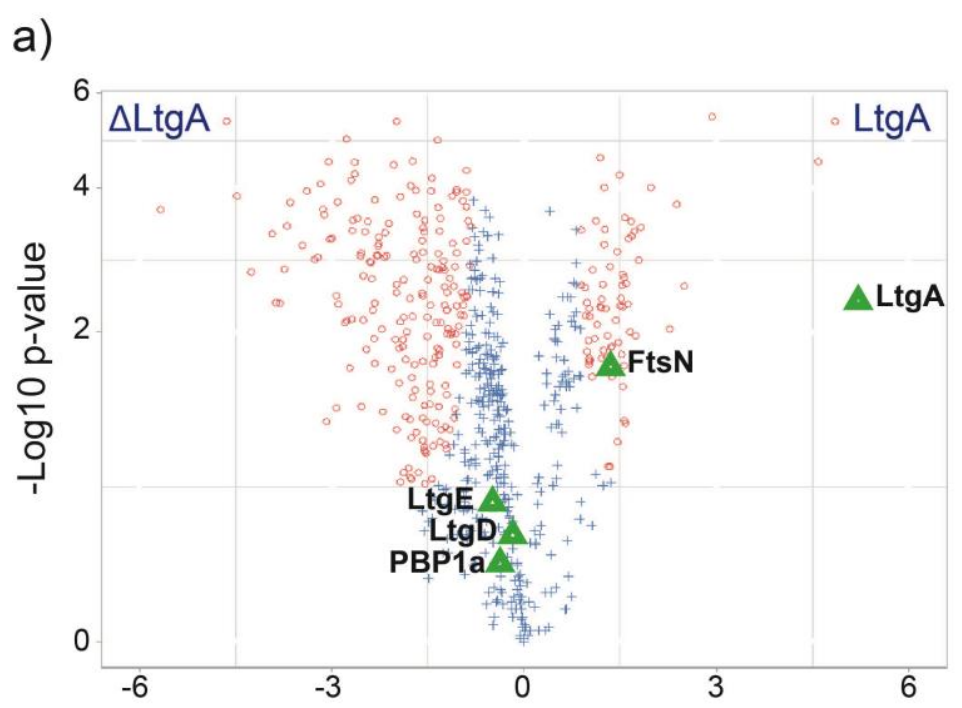

log2 Fold change following LtgA immunoprecipitation

b)

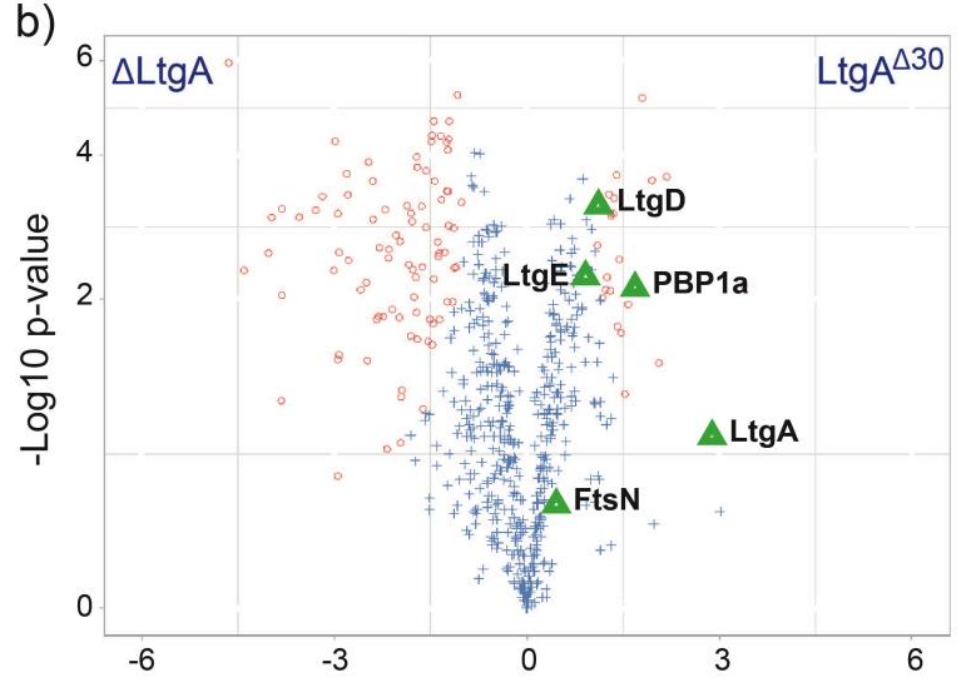

log2 Fold change following LtgA immunoprecipitation

299 a) Volcano plots of proteins enriched in $\Delta \operatorname{ltg} A^{\operatorname{ltg} A}$ versus $\Delta \operatorname{ltg} A$ strains. b) Volcano plots 300 of proteins enriched in $\Delta \operatorname{ltg} A^{\operatorname{ltg} A \Delta 30}$ versus $\triangle \operatorname{ltg} A$ strains. Coimmunoprecipitation 301 experiments were performed with each strain in triplicate. The strains utilized were $\Delta \lg A, \Delta \operatorname{ltg} A^{\operatorname{ltg} A}$ and $\Delta \operatorname{ltg} A^{\operatorname{ltg} A \Delta 30}$. LC-MS/MS was used to identify proteins. Volcano plots

303 depict significance versus fold change on the $y$-and $x$-axes, respectively. Data points with 304 low (significant) p-values appear closer to the top of the plot (for p-values see 305 Supplementary Table 2). Changes in both directions (enrichment and lack of enrichment) appear equidistant from the center on the $\mathrm{x}$-axis. 


\section{Validation of LtgA interactors}

Since increased levels of $O$-acetylated and non-crosslinked PG subunits were the most striking phenotypes of the $\Delta \lg A^{\operatorname{ltg} A \Delta 30}$ mutant strain, we used gel filtration binding

311 studies to identify and confirm potential interactors of $\operatorname{Ltg} A$ that could be responsible for

312 the observed aberrations in the composition of the PG. Ape1 the PG-de- $O$-acetylase (not

313 significantly enriched in the co-immunoprecipitation studies) and other identified glycan

314 strand synthesis or modifying enzymes (LtgE, and PBP1a) was chosen for further

315 validation (Fig. 6a-e). PBP2 (FtsI) of Neisseria species is a homolog of PBP3 of E. coli,

316 and in complex with FtsW is the putative PG polymerase of the divisome. PBP2 has

317 transpeptidase activity and was not enriched in our screen, but was included in this study

318 because PBP3 from E. coli was reported to form protein complex with Slt70 an homolog

319 of $\operatorname{Ltg} \mathrm{A}^{28}$. We first purified Ape1, LtgA, LtgE, PBP1a and PBP2 following their

320 heterologous expression in E. coli (Fig. 6a,c-e, Supplementary Figure. 7). Each enzyme

321 was purified individually and then combined prior to their application to size-exclusion

322 columns (Fig. 6a-e). LtgA formed a 100-kDa complex with Ape1 and a 150-kDa complex 323 with PBP1a (Fig. 6a, c-e).

$324 \quad$ LtgE is an approximately $72-\mathrm{kDa}$ protein that is similar in molecular weight to

325 LtgA (Fig. 6e). LtgE has two domains, namely, an N-terminal bacterial muramidase

326 lysozyme-like domain and a LysM-like peptidoglycan-binding C-terminal domain (Fig.

327 6e). Because the full-length protein was recalcitrant to expression in E. coli, we

328 successfully expressed instead the approximately 36-kDa N-terminal domain of LtgE

329 which is prone to proteolytic degradation (Fig. 6e). However, the 36-kDa N-terminal

330 domain of $\operatorname{LtgE}$ selectively binds $\operatorname{LtgA}$ to form an approximately 100-kDa complex with

331 LtgA(Fig. 6e). Finally, the oligomeric PBP2 and monomeric LtgA was eluted as separate

332 species, suggesting that there was no strong association between the two, validating the

333 absence of significant enrichment in our coimmunoprecipitation study. 
a)

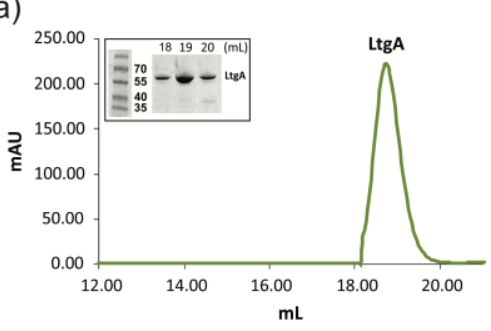

c)

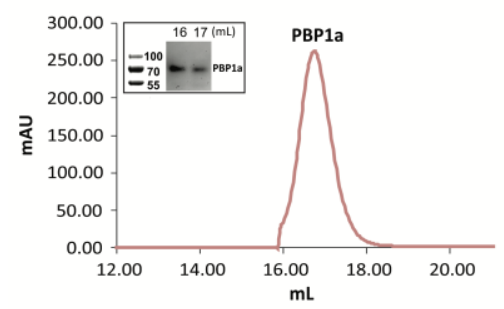

d)

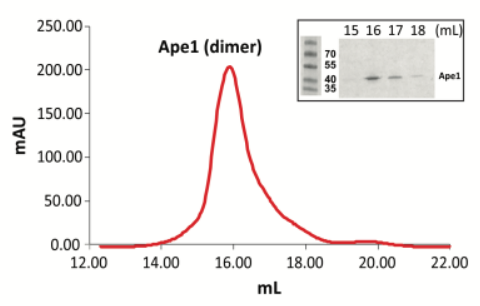

e)

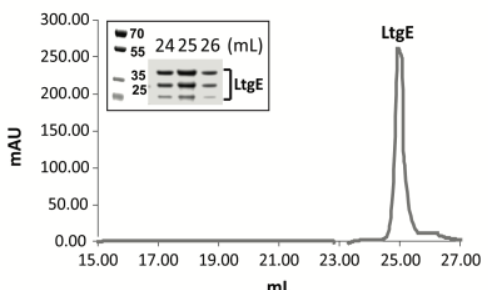

b)
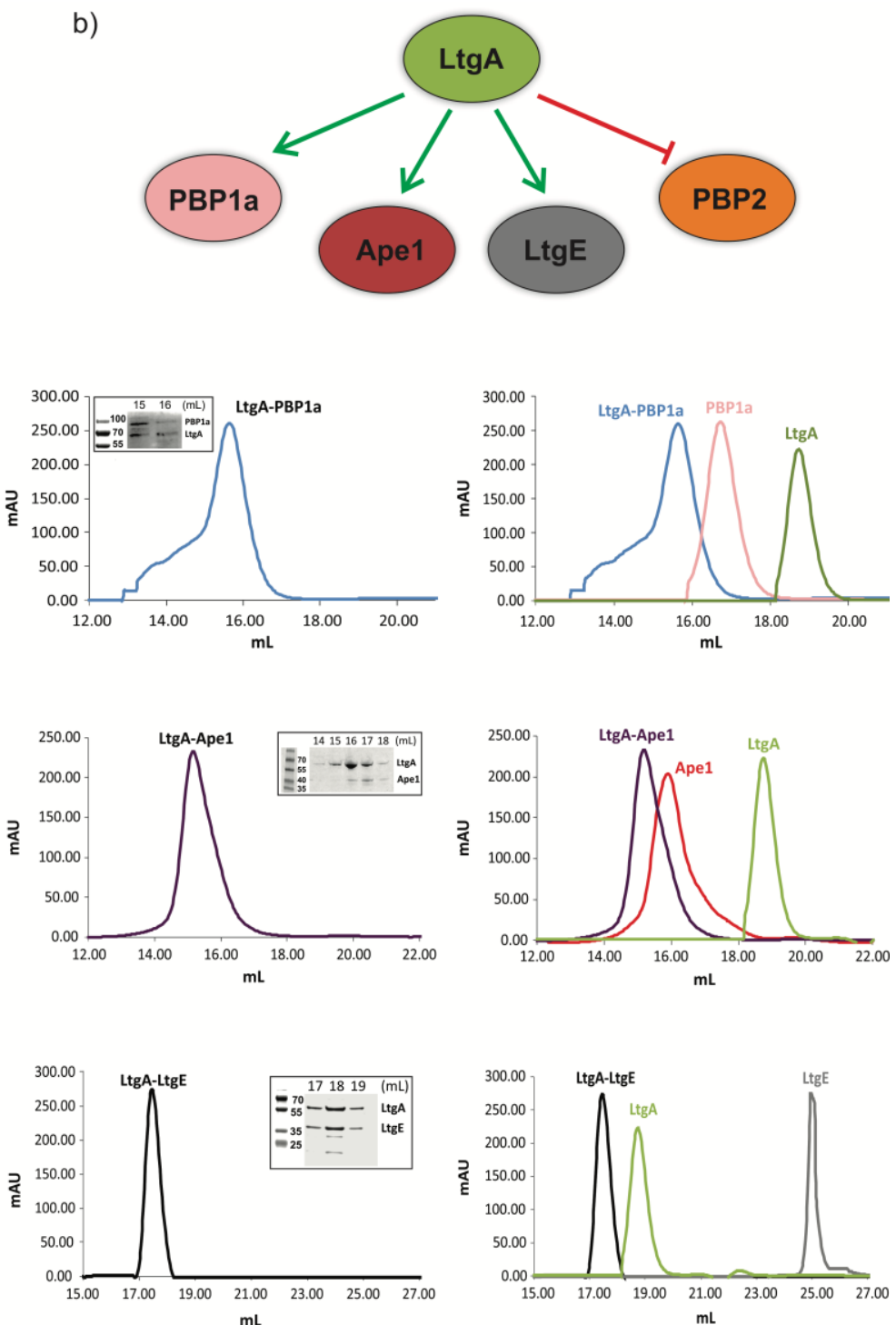

Figure 6. Validation of the LtgA PG-centric interactome.

a) Chromatogram showing size exclusion analysis of LtgA (65 kDa, green). Each inserts represents an SDS-PAGE analysis of peak fractions containing proteins. Lanes are labeled with corresponding volumes. b) Summary of the validated LtgA PG-centric interactome. c, d, e) (Left panel) Chromatogram showing size exclusion analysis of LtgA interacting partners: PBP1a (85 kDa, pink), Ape1 (40 kDa, red) and LtgE N-terminal bacterial muramidase lysozyme-like domain (36 kDa, gray). (Middle panel)

Chromatogram showing size exclusion analysis of the corresponding complexes with LtgA: PBP1a-LtgA (150 kDa, blue), Ape1-LtgA (105 kDa, purple) and LtgE-LtgA (101 $\mathrm{kDa}$, black), respectively. Inserts are SDS-PAGE analysis of peak fractions containing 
348 LtgA protein complexes is shown in the inserts. (Right panel) Overlay of the

349 chromatograms corresponding to purified LtgA, binding partners, and LtgA protein

350 complexes.

351

352

353

The impact of protein complexes on peptidoglycan $O$-acetylation

Hyperacetylation of the PG was the most striking phenotype of the $\Delta \operatorname{ltg} A^{\operatorname{ltg} A \Delta 30}$ strain, therefore we explored whether the normal function of Ape 1 depends on LtgA or if Ape1 and LtgA work in concert enzymatically to de- $O$-acetylate the PG. To accomplish this, we examined the processivity of LtgA and Ape1 against acetylated PG from $N$. meningitidis or the activity of an Ape1 and Ape1 combined with LtgA toward 4nitrophenyl acetate, a previously characterized substrate of Ape1 from $N$. gonorrhoeae that is not a substrate for $\operatorname{Ltg} \mathrm{A}^{42,43}$.

In the presence of equimolar $(1.2 \mu \mathrm{M})$ amounts of Ape1, LtgA degrades the PG more efficiently (Supplementary Fig. 7), this is consistent with previous studies that suggest $O$-acetylation blocks the function of LTs and lysozyme $\mathrm{PG}^{17,22,23,44}$. Surprisingly, in the absence of a common substrate and utilizing equimolar amounts (12 nM) of LtgA and Ape1, LtgA stabilizes and enhances the activity of Ape1. The reaction remained well within the linear range for 60 minutes when both enzymes were present, which was in stark contrast to Ape1, that showed less activity over the time course of 60 minutes. These data demonstrate that the enzymatic activities of LtgA and ApeI are enhanced reciprocally when functioning together in a complex (Supplementary Fig. 7a-b). It also appears that LtgA stabilizes and enhance the activity of Ape1.

\section{Role of alpha helix 30 in the virulence of $N$. meningitidis}

In N. meningitidis and $N$. gonorrhoeae, the activity of LtgA and other LTs leads to a release of cytotoxic PG fragments, which are detected by the host and induce a Nod1-dependent inflammatory response ${ }^{45-48}$. Since the alpha helix 30-deleted strain of LtgA compromised the PG composition and caused enrichment of the protein partners involved in the PG machinery of enzymes, the functional role of the alpha helix was explored in vivo in a mouse infection model. For this purpose, we used transgenic mice expressing human transferrin as an experimental model that allows meningococcal growth by providing a human iron source during infection. The four $N$. meningitidis 
379 strains (wild-type, $\Delta \operatorname{ltg} A^{\operatorname{ltg} A}, \Delta \operatorname{ltg} A^{\operatorname{ltg} A \Delta 30}$ and $\triangle \operatorname{ltg} A$ ) were used to infect the mice by

380 intraperitoneal injection. Two hours after infection, the four strains induced similar levels

381 of bacteremia (Fig. 7a), suggesting that the strains were not defective in their ability to

382 reach the bloodstream. The $\Delta \operatorname{ltg} A$ strain appears to be cleared more slowly. However, the

$383 \Delta \operatorname{ltg} A^{\operatorname{ltg} A \Delta 30}$ strain was cleared from the blood at a significantly faster rate than the other

384 strains, exhibiting a 2-log difference in colony forming units (CFUs) at the 6-h time point

385 compared to the wild-type strain (Fig. 7a). These results were also consistent with those

386 at the cytokine production level, as the $\Delta \lg A^{\operatorname{ltg} A \Delta 30}$ strain exhibited significantly

387 decreased levels of IL-6 and KC (the functional murine homolog of human IL-8) $6 \mathrm{~h}$ after

388 infection, while all the isolates exhibited similar levels $2 \mathrm{~h}$ after infection (Fig. 7b).

389 Overall, the $\Delta \operatorname{ltg} A^{\operatorname{ltg} A \Delta 30}$ strain displays impaired fitness in the host, suggesting $\operatorname{Ltg} \mathrm{A}$

390 could play a key role in bacterial virulence. 
a)

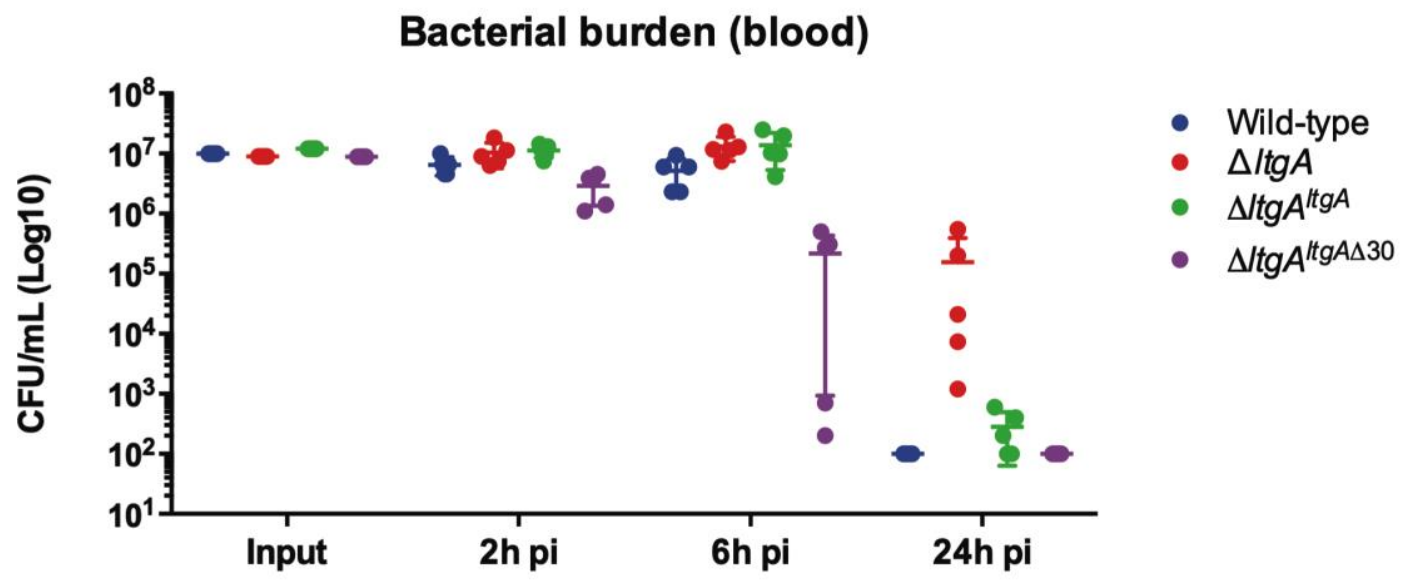

b)

Figure 7. Helix 30 of LtgA plays a role in Neisseria meningitidis host adaptation and
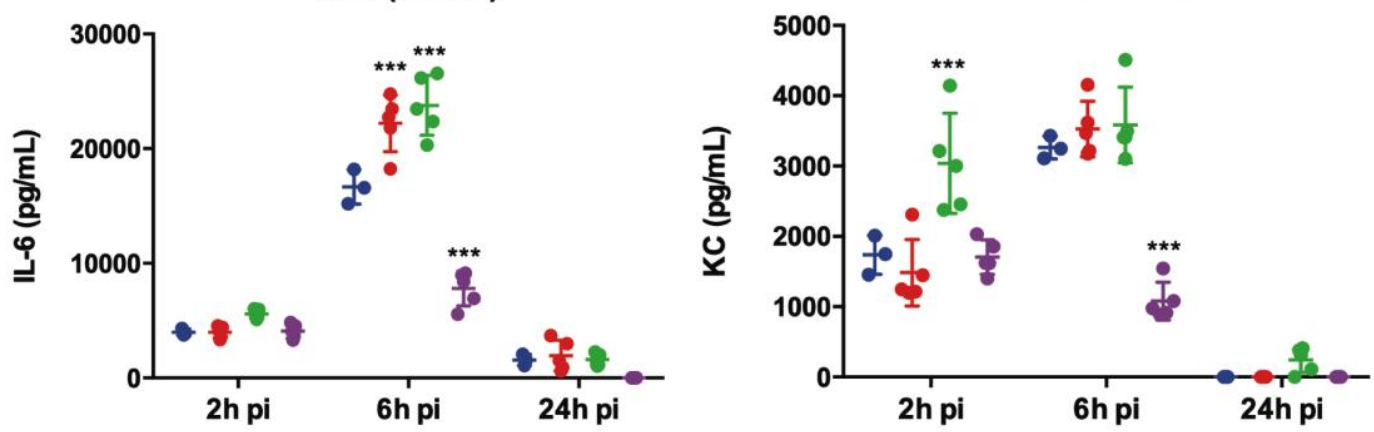

- Wild-type

- $\Delta \operatorname{ltg} A$

- $\Delta \operatorname{tg} A^{\operatorname{ltg} A}$

- $\Delta \operatorname{tg} A^{\operatorname{ltg} A \Delta 30}$

$N$. meningitidis wild-type, $\Delta \operatorname{ltg} A, \Delta \operatorname{ltg} A^{\operatorname{ltg} A}$ and $\Delta \operatorname{ltg} A^{\operatorname{ltg} A \Delta 30}$ were administered to transgenic mice expressing human transferrin via intraperitoneal route. (a) Bacterial burden was determined by CFU enumeration in blood 2, 6 and $24 \mathrm{~h}$ pi. These data shows that the strain complemented with a deletion in helix 30 is cleared faster than the other strains. (b) Pro-inflammatory cytokine (IL-6) and chemokine $(\mathrm{KC})$ profile in blood of infected mice was evaluated 2, 6 and $24 \mathrm{~h}$ post infection by ELISA. $\Delta \operatorname{ltg} A^{\operatorname{ltg} A \Delta 30}$ induced lower levels of inflammatory mediators production upon infection 


\section{Discussion}

Antibiotic resistance is recognized as an urgent global public health threat. One potential solution is to develop new treatment strategies that impact multiple cellular targets and consequently, circumvent the rise of antibiotic resistance. The bacterial cell wall is assembled by a number of enzymes, some of which are broadly categorized as PG polymerases, PG-modifying enzymes and PG hydrolases. The primary targets of $\beta$-lactams, clinically the most utilized antibiotics, are PBPs that are known to polymerize PG. The development of a combinatorial or single therapy that interferes with multiple cellular function of the PG machinery could define a new era in antibiotic development. This would be particularly relevant for $N$. gonorrhoeae infections, as no vaccines against this species are currently available, and highly resistant strains are on the rise. Indeed, a $N$. gonorrhoeae "superbug" has already been identified that does not respond to the usual treatment with $\beta$-lactams such as ceftriaxone ${ }^{49}$.

In this study, we identified a variant of $\operatorname{Ltg} \mathrm{A}$ with a disordered active site alpha helix 30, which is important for PG binding and for the catalytic mechanism of $\operatorname{Ltg} A$ (Fig. 1b, movie 1). LTs are highly redundant enzymes, and when individual or multiple LTs are deleted, bacteria are known to proliferate normally because others LTs compensate for the loss of activity and/or function $^{45,50}$. Interestingly, when 6 LTs were deleted from $E$. coli, only a mild chaining phenotype was observed $^{13}$, however a mutant of $\operatorname{ltg} C$ with a 33-bp deletion at the $5^{\prime}$ end from Neisseria sp., showed defects in growth and daughter cell separation ${ }^{51}$. In our $\Delta \operatorname{ltg} A^{\operatorname{ltg} A \Delta 30}$ strain, we observed significant defects in growth, cell division, cell separation, cell membrane irregularities, and fibrous and membranous extra cellular material, which were noticeably absent in the wild type, $\Delta \operatorname{ltg} A$, and the $\Delta \operatorname{ltg} A^{\operatorname{ltg} A}$ strains (Fig. 2, 3, Supplementary Fig. 3a-b). LtgA has been shown to localize to the septum, but no phenotype associated with cell division or cell separation was previously reported. However, the expression of an LT with impaired function $\left(\operatorname{Ltg} \mathrm{A}^{\Delta 30}\right.$ ) results in the perturbation of various processes that are essential for bacterial proliferation.

Having observed that the $\Delta \operatorname{ltg} A^{\operatorname{ltg} A \triangle 30}$ strain, but not the $\triangle \operatorname{ltg} A$ strain, was defective in growth, cell separation, and cell division, we hypothesized that this pleiotropic phenotype could arise because the defective LtgA enzyme continues to participate in PG biosynthesis complexes (Fig. 3, Supplementary Fig. 3a-b). This could lead to aberrant activities by LtgA interaction partners, which compromise the fitness of the bacterium. We first analyzed the PG profiles of wild-type $N$. meningitidis, $\Delta \operatorname{ltg} A, \Delta \operatorname{ltg} A^{\operatorname{ltg} A}$ and $\Delta \operatorname{ltg} A^{\operatorname{ltg} A \Delta 30}$, and observed that $\Delta \operatorname{ltg} A^{\operatorname{ltg} A \Delta 30}$ strain was hyperacetylated and there was an increase in PG monomers (Fig.4, Table 1). To identify protein assemblies that could be responsible for these abnormalities, we examined the LtgA interactome using co-immunoprecipitation and gel filtration chromatography. We identified four 
enzymes, PBP1a, Ape1, LtgE (an E. coli MltD homolog) and LtgD (an E. coli MltB homolog) that interact with LtgA (Fig. 5a-b, 6a-e, and Supplementary Table 2). Incidentally, Ape1, LtgE and LtgD similar to LtgA are PG glycan strand modifying enzymes and one of the activities of the bifunctional PBP1a is to polymerize the PG glycan strand. Interestingly, PBP2 with known transpeptidase activity did not interact with LtgA using gel filtration binding studies. Together (LtgA, LtgE, LtgD, Ape1, PBP1a,) appear to form the nucleus of the PG glycan strand remodeling machinery. Interestingly, consistent with our observation, PBP1a, LtgE, and LtgA all appear to have co-evolved because they are co-conserved in all the proteobacteria that were surveyed (Supplementary Fig. 8). It should be noted that the betaproteobacteria have two slightly diverged PBP1a genes, but this was not the case for Neisseria (Supplementary Fig. 8). On the other hand, Ape1 was exclusively found in Neisseria, Kingella, Snodgrassella, Morococcus, Azovibrio, and one isolate of Burkholderia ubortensis, suggesting Ape1 was potentially acquired later by lateral gene transfer (Supplementary Fig. 8).

The hyperacetylation of the PG was the most striking phenotype. The interaction of LtgA with Ape1 is not completely unexpected because Ape1, a PG-de- $O$-acetylase, removes the $O$ acetyl group from the C6-hydroxyl position of the glycan strand of $O$-acetylated PG and ensures the proper metabolism of the PG by LTs (LtgA, LtgD or LtgE and others) ${ }^{17,22,23,44}$. We hypothesized that LtgA stablizes the function of Ape1 and potentially the hub of glycan chain targeting enzymes that are known to be crucial for the proper metabolism of the PG (Fig. 6a-e). To test this, we used 4-nitrophenyl acetate, a known substrate of Ape1 but not LtgA. Surprisingly, LtgA stabilizes the activity and function of Ape1 well past the normal range $(1 \mathrm{hr})$ of most in vitro enzymatic reactions, giving clear evidence that LtgA could orchestrate the activity, stability and function of Ape1 (Supplementary Fig. 7). Our study revealed an intimate relationship between the LtgA and Ape1, ie. LtgA stabilizes or regulates the function of Ape1 and an impaired LtgA appears to poison the PG machinery with devastating effects toward the survival of Neisseria. Interestingly, the trapped complexes represent sub-complexes that are a part of the known enzymatic cell wall glycan strand machinery (Fig. 5a-b and Fig. 6a-e). These results provide additional insight into the coordination of the activities of PG-associated enzymes during cell wall biosynthesis.

A rather surprising discovery from the interactome study was that LtgA interacts with LtgE (Fig. 5a-b). To our knowledge, this study is the first to show that LTs form protein complexes with each other. LTs can be categorized as enzymes with endolytic or exolytic activities. Although the activities of LTs are known to be redundant, the fact that these enzymes can coordinate their activities in a complex was previously unknown. Both the endolytic and 
exolytic activities of LTs are needed for the recycling of PG or for the release of cytotoxic PG monomers. The endolytic enzyme ( $\operatorname{LtgE}$ ) cleaves middle of the glycan strands, and the exolytic enzymes ( $\operatorname{Ltg} \mathrm{A}$ or $\operatorname{Ltg} D$ ) cleave the end of the $\mathrm{PG}$ strands ${ }^{1}$. Specifically, deletion of $\operatorname{ltg} A$ and $\operatorname{ltg} D$ genes resulted in a major decrease in the production of the cytotoxic PG monomers, while $\operatorname{ltg} E$ deletion did not affect PG monomer release ${ }^{45,48}$.

We also demonstrated that the bifunctional PBP1a interacts directly with LtgA (Fig. 6c). PBP1a is the first identified PG polymerase and the current major target of known antibiotics (Fig. 6c). In addition, we observed an enrichment of FtsN, a cell division protein that activates septal PG synthesis and constriction of the cell, in the strain expressing native $\operatorname{Ltg} \mathrm{A}^{52-55}$. Bacterial two-hybrid studies have shown that FtsN interacts with the E. coli divisome machinery, including the PG polymerase complex, FtsW-PBP3 (Neisseria, PBP2), FtsQ, and FtsA ${ }^{34,55-57}$. The nuclear magnetic resonance structure of FtsN of E. coli reveals that it is a bitopic membrane protein with a small cytoplasmic portion and a large domain on the periplasmic face ${ }^{58}$. Future studies could establish whether, the periplasmic portion of FtsN interacts either directly or indirectly with LtgA and other periplasmic proteins. LtgA is localized at the septum ${ }^{15,24}$, and FtsN activates septal PG synthesis at the cell division site. Therefore LtgA could be connected to the divisome machinery through FtsN. This could be one of the explaination as to why an impaired LtgA appears to disrupt the normal course of cell division and cell separation.

Finally, to understand what role a defective LtgA that interferes with the normal function of the PG machinery plays in the pathogenesis of $N$. meningitidis we used a mouse infection model and showed $\triangle \operatorname{ltg} A^{\operatorname{ltg} A \triangle 30}$ strain of type $N$. meningitidis was cleared from the blood at a significantly faster rate than the wild-type, $\Delta \operatorname{ltg} A^{\operatorname{ltg} A}$ or $\triangle \operatorname{ltg} A$ strains. Consistent with the virulence phenotype, and in comparison to the other three strains, the $\Delta \operatorname{ltg} A^{\operatorname{ltg} A \triangle 30}$ exhibited significantly decreased levels of IL-6 and KC, $6 \mathrm{~h}$ post-infection (Fig. 7b) indicating a general loss of fitness of the helix-30 deleted mutant. Unexpectedly, the $\Delta \operatorname{ltg} A$ strain cleared the blood stream at a slower rate than the wild-type, $\Delta \operatorname{ltg} A^{\operatorname{ltg} A \Delta 30}$ or the $\Delta \lg A^{\operatorname{ltgA}}$. However, the levels of the cytokine IL- 6 and $\mathrm{KC}$ were comparable to that of the wild-type or the complemented strain. A deletion of both $\operatorname{ltg} A$ and $\operatorname{ltg} D$ in $N$. gonorrhoeae eliminates the release of cytotoxic PG monomers ${ }^{14,59}$. In our study, we deleted only $\operatorname{ltg} A$ and therefore the expression of $\operatorname{Ltg} D$ continues to release soluble monomeric muropeptides, that could drive inflammation, while $\Delta \operatorname{ltg} A^{\lg A \Delta 30}$ has a larger defect in the PG machinery. Additionally, the $\Delta \lg A^{\operatorname{ltg} A \Delta 30}$ strain is hyperacetylated, suggesting Ape 1 the PG de $O$-acetylase was nonfunctional. It is known that $O$-acetylation blocks the collective activity of all LTs and compounded by the dysfunction of Ape1 this could explain 
the pro-inflammatory potential of the $\Delta \operatorname{ltg} A^{\operatorname{ltg} A \triangle 30}$ mutant. Furthermore, the $\Delta \operatorname{ltg} A^{\operatorname{ltg} A \triangle 30}$ mutant bacteria form aggregates, potentially rendering them more susceptible to killing by phagocytes, and therefore cleared from the host more quickly than the other strains.

The initial innate host response to a $N$. meningitidis systemic infection is mediated by LPS sensing through TLR4, which would be the same for WT and $\triangle \operatorname{ltg} A$ mutant. Therefore, the WT and $\triangle \operatorname{ltg} A$ strains would have the same pro-inflammatory potential. However, clearing of the $N$. meningitidis infection is the result of effective activation of phagocytes such as neutrophils and it has been shown that efficient activation of neutrophils requires Nod1 sensing ${ }^{60},{ }^{61}$. Impaired release of monomeric muropeptides by the $\Delta \operatorname{ltg} A$ mutant strain, resulting in reduced Nod1 activation, could explain why the $\Delta \operatorname{ltg} A$ strain is cleared more slowly than the wild-type bacteria. Overall, these finding suggests that LtgA and possibly other LTs, plays a primary role in the life cycle of the cell, and regulate the function of other PG glycan strand specific enzymes that ensures the proper function of the cell wall machinery.

In summary, a mechanistic role for LtgA and other LTs emerges, whereby together with other PG modifying (LtgE, LtgD, Ape 1) or polymerization (PBP 1a) enzymes, they form the nucleus of the PG glycan strand remodeling machinery that is essential for the insertion of new material during growth. Ape1, a PG-de- $O$-acetylase, removes the $O$-acetyl group from the C6hydroxyl position of the glycan strand (Fig. 8). Ape1's function is regulated and stabilized by LtgA possibly because their functions are symbiotic. The removal of the $O$-acetyl group by Ape 1 allows LtgA and LtgE to continue metabolism of the PG (Fig. 8). The endolytic enzyme ( $\operatorname{LtgE}$ ) likely cleaves internal sites on the glycan strands meanwhile, the exolytic enzyme (LtgA) cleaves the end of the PG glycan strands. The bifunctional PBP1a polymerizes the insertion of new material after remodeling or degradation (Fig. 8). Meanwhile, FtsN although not addressed experimentally in this paper likely connects LtgA to the cell division site and the PG polymerization machinery (FtsW-PBP2). An impaired LtgA disrupts the normal course of bacterial cell division or cell separation paving the way for the design of inhibitors or antibiotics that target LTs. 


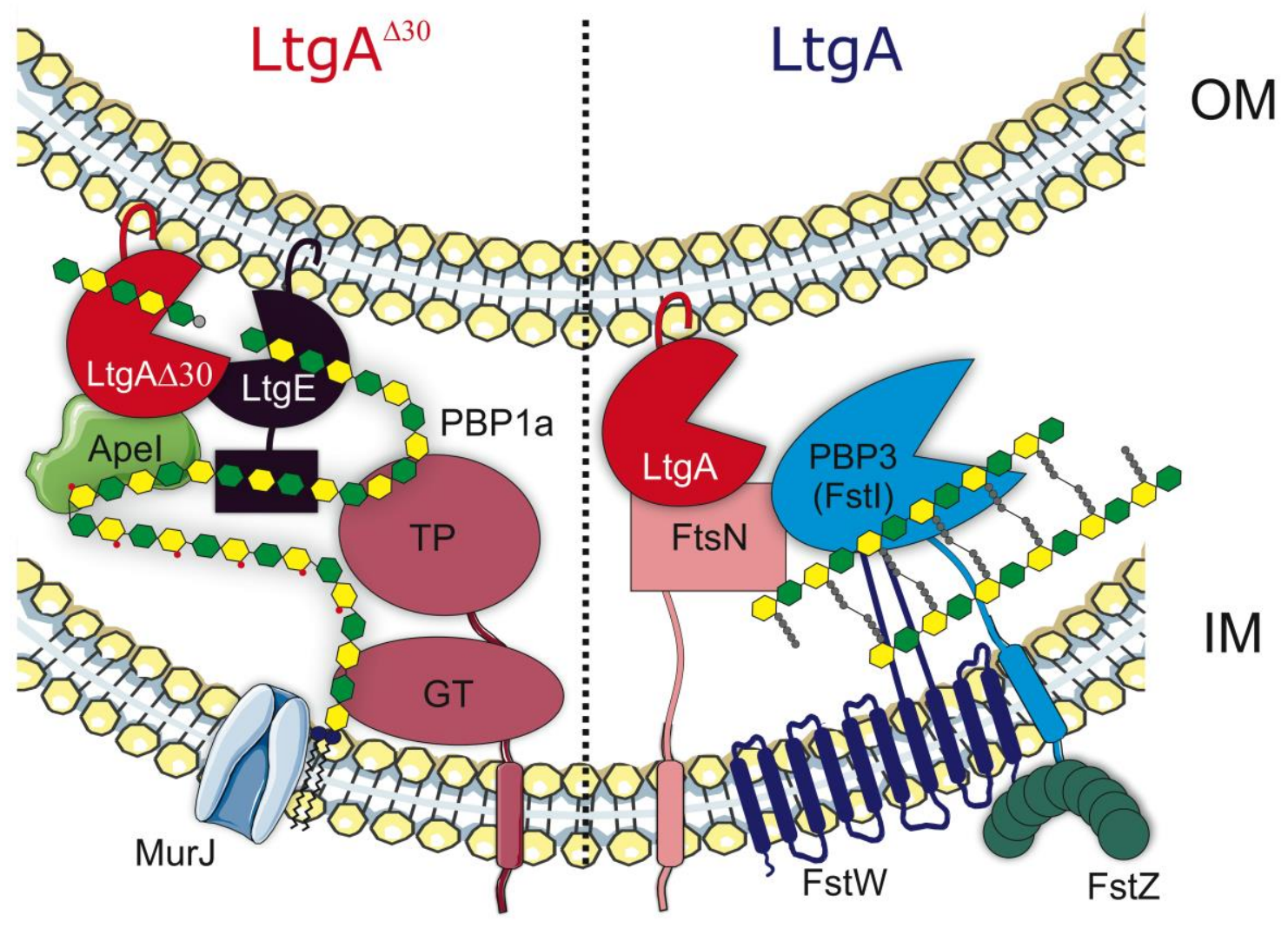

Figure 8. The proposed role of the essential PG centric protein hub directed by LtgA.

The panel labelled $\operatorname{Ltg} \mathrm{A}^{\Delta 30}$ reveals the core of the glycan strand remodelling machinery,

whereby Ape1 removes the $O$-acetyl group from the C6-hydroxyl position of the glycan strand.

The removal of the $O$-acetyl group by Ape 1 allows LtgA and LtgE to metabolize the PG. The endolytic enzyme (LtgE) cleaves nascent glycan strands and the exolytic enzyme (LtgA) cleaves old PG strands. The bifunctional PBP1a polymerizes the PG. The panel labeled LtgA decribed how FtsN connects LtgA to the PG synthesis at the cell division site.

\section{Conclusion}

We devised a multidisciplinary approach using structural biology to show that it is possible to target a 'hot spot' on an LT in order to affect bacterial growth, cell division, and cell membrane integrity, which resulted in lethal consequences for the bacteria during host infection. Additionally, as we discovered with Ape1, LTs can regulate the function and activity of its binding partners. Our study further suggests that although the bacteria devised a safety net system of redundant LTs that were previously deemed non-essential to bacterial survival, we demonstrate that traditional ways of assessing their essentiality does not apply. However, inactivation of an LT primarily guided by structural knowledge of how it interacts with its substrates or protein partners helped to reveal its role in the bacterium. This study shows the ripple effects of disrupting LtgA PG binding capabilities and sets the stage for future development of a class of antibiotics that may 
act by a dual action in vivo. A small molecule binding to alpha helix 30 could interfere with growth and simultaneously promote bacterial clearance, mimicking the enhanced clearance of the $\triangle \operatorname{ltg} A^{\operatorname{ltg} A \triangle 30}$ mutant in a murine infection model.

\section{Methods}

\section{Protein expression and purification}

All constructs were created using standard molecular biological techniques. All constructs used for protein expression and purification in this study were GST fusions expressed from pGEX-4T1 (GE Life Sciences). The native proteins without signal peptides were expressed in BL21(DE3) Gold competent cells (Novagen). The gene encoding the LtgA deletion mutant lacking the alpha helix ${ }^{503}$ (ATAREIAGKIGMD) ${ }^{513}$ was chemically synthesized by ProteoGenix. The synthesized $\operatorname{ltg} A$ deletion gene was cloned into a GST-fusion pGEX-4T1 (GE Life Sciences) plasmid as described above. The expression of all constructs was induced with $0.6 \mathrm{mM}$ IPTG at an optical density at 600nm (OD600) of 0.7-0.8 and harvested after $4 \mathrm{~h}$ of induction at $18^{\circ} \mathrm{C}$. After glutathione-affinity chromatography and thrombin cleavage, proteins were purified to homogeneity by size-exclusion chromatography (Superdex-200, GE) in 50 mM HEPES (pH 7.4), $150 \mathrm{mM} \mathrm{NaCl}$, and $1 \mathrm{mM} \mathrm{BME}$. After gel filtration, the proteins were immediately used for crystallization or flash frozen in liquid nitrogen and stored at $-80^{\circ} \mathrm{C}$.

\section{X-ray crystallography}

Crystallization screening was carried out by the sitting-drop vapor-diffusion method with a Mosquito $^{\circledR}$ (TTP Labtech) automated crystallization system. All crystals were grown at $18^{\circ} \mathrm{C}$ using the hanging-drop vapor-diffusion method. Crystals of $15-20 \mathrm{mg} / \mathrm{ml} \mathrm{LtgA}$ were grown at $18^{\circ} \mathrm{C}$ and appeared within 2-3 days. $\operatorname{Ltg} \mathrm{A}$ was crystallized in a 1:1 (v/v) ratio against a well solution of 33\% (w/v) PEG 6000 and 100 mM HEPES, pH 7.5. Crystals were rectangular in shape and grew to approximately $200-300 \mu \mathrm{m}$ in length.

The data set was collected at the Soleil Synchrotron (Beamline Proxima-1) (Supplementary Table 3). Phasing by molecular replacement was performed using Phenix ${ }^{62}$. Building was performed using $\operatorname{Coot}^{63}$, and restrained refinement was carried out using a combination of Phenix and the ccp4 software suite ${ }^{62,64}$. MolProbity was used during building and refinement for iterative structure improvements ${ }^{65}$.

All structural figures were generated with PyMOL (PyMOL Molecular Graphics System, version 1.5, Schrödinger, LLC). The crystallographic parameters, data statistics, and refinement statistics are shown in Supplementary Table 3. Modeling of unknown LTs were accomplished 
using Phyre $2^{66}$. Movies of the LtgA enzymatic steps was generated in PyMOL and then assembled in photoshop and edited in iMovie.

\section{Protein-protein interaction studies by gel filtration}

To explore the interactions of LtgA and its PG binding partners, proteins were mixed at equimolar concentrations of $10 \mu \mathrm{M}$, incubated on ice for $1 \mathrm{~h}$, and subjected to gel-filtration chromatography on an SD200 10/300 column. Approximately 150-300 $\mu$ l of each sample was applied to the column in $50 \mathrm{mM}$ HEPES (pH 7.5) and $150 \mathrm{mM}$ salt. Peak fractions were then subjected to analysis 5-15\% SDS-PAGE.

\section{Analysis of Neisseria sp. peptidoglycan by reversed-phase HPLC and mass spectrometry}

The peptidoglycan isolated from all four strains peptidoglycan (wild-type, $\Delta \operatorname{ltg} A, \triangle \operatorname{ltg} A^{\operatorname{ltg} A}$ and $\Delta \operatorname{ltg} A^{\operatorname{ltg} A \Delta 30}$ ) was incubated for $16 \mathrm{~h}$ in the presence of $10 \mu \mathrm{g}$ of mutanolysin in $12.5 \mathrm{mM}$ sodium phosphate buffer ( $\mathrm{pH} 5.8$ ) at $37^{\circ} \mathrm{C}$ (total reaction volume $150 \mu \mathrm{l}$ ). The reaction was stopped by boiling the samples for $3 \mathrm{~min}$, and the supernatant containing the soluble muropeptides was collected after centrifugation at $16,000 \times g$ for $10 \mathrm{~min}$. The supernatant was analyzed by reversed-phase HPLC using a Hypersil GOLD aQ column (5 $\mu \mathrm{m}$ particle size, $150 \times$ $4.6 \mathrm{~mm}$, flow rate $0.5 \mathrm{ml}$ at $52^{\circ} \mathrm{C}$, Thermo Fisher Scientific) with a mobile phase of $\mathrm{H}_{2} \mathrm{O}-0.05 \%$ trifluoroacetic acid and a 25\% acetonitrile gradient over 130 min. Muropeptides of interest were collected and identified by mass spectrometry as previously described ${ }^{4,5}$.

\section{Bacterial strains}

Clone 12 is a derivative of strain 8013, a serogroup C N. meningitidis $\operatorname{strain}^{67}$, and MC58 is a serogroup B strain $^{68}$. Bacteria were grown on GCB medium (Difco) containing Kellogg's supplements ${ }^{69}$. The E. coli strain $\mathrm{DH} 5^{70}$ was used for plasmid preparation and subcloning. Kanamycin, ampicillin and erythromycin were used in E. coli at final concentrations of 50, 100 and $300 \mu \mathrm{g} / \mathrm{ml}$, respectively. In $N$. meningitidis, kanamycin, ampicillin and erythromycin were used at final concentrations of 100,20 and $2 \mu \mathrm{g} / \mathrm{ml}$, respectively.

\section{Plasmid construction}

The $\operatorname{ltg} A$ gene (1851 nucleotides according to the genome sequence of the meningococcal strain MC58) was chemically synthesized with a deletion of 42 bp (14 codons) between positions 1506 (codon 502) and 1548 (codon 516) (starting at ATG) and was cloned into the vector pUC57 to generate the recombinant plasmid pUC57ltgA (ProteoGenix, Schiltigheim, France). The ltgA 
fragment was amplified using the primer pair NMF1/NMR1 from the plasmid pUC57ltgA and from the strain MC58. The two fragments were blunt-ended using the Klenow DNA polymerase fragment (BioLabs) and subcloned into the BamHI site of the recombinant plasmid pTE-KM ${ }^{71}$. This plasmid contains the pilE gene of clone 12 with the $\mathrm{Km}$ cassette, encoding resistance to kanamycin, located immediately downstream of the pilE without modification of pilE expression. Moreover, a unique BamHI site located between the $\mathrm{Km}$ cassette and the downstream region at the 3' end of the pilE gene ${ }^{67,71}$ was used to subclone the two blunt-ended fragments from the plasmid pUC571tgA and from the strain MC58 to yield the recombinant plasmids pD- $\operatorname{ltg} A^{\operatorname{ltg} A}$ and $\mathrm{pD}-\Delta \operatorname{ltg} A^{\operatorname{ltg} A \triangle 30}$, respectively.

An internal deletion in the $\operatorname{ltg} A$ gene was also constructed by removing the segment between the restriction sites BsmI (position 21) and BalI (position 1724) on pUC57ltgA, and this region was replaced with the $\operatorname{erm} A M$ cassette, encoding erythromycin resistance; the construct was checked using the primer pair ERAM1/ERAM3 (5'-gcaaacttaagagtgtgttgatag-3' and 5'aagcttgccgtctgaatgggacctctttagcttcttgg-3', respectively $)^{71}$. The corresponding recombinant plasmid pDG15-09 was linearized at the EcoRI site of the pUC57 vector and used to transform the clone 12 strain of $N$. meningitidis. Transformants were selected on standard GCB medium in the presence of $2 \mu \mathrm{g} / \mathrm{ml}$ erythromycin. Integration by homologous recombination into the $\operatorname{ltg} A$ gene on the meningococcal chromosome was further confirmed by PCR analysis using the oligonucleotides ERAM1/ERMA3 and NMF1/NMR1. One transformant was selected for further analysis and named pD- $\Delta \operatorname{ltg} \mathrm{A}$.

The two recombinant plasmids $\mathrm{pD}-\Delta \operatorname{ltg} A^{\operatorname{ltg} A}$ and $\Delta \operatorname{ltg} A^{\operatorname{ltg} A \Delta 30}$ were linearized using the ScaI restriction enzyme and used to transform the strain $\mathrm{pD}-\Delta l \operatorname{tg} A$. Transformants were selected on standard GCB medium in the presence of $2 \mu \mathrm{g} / \mathrm{ml}$ erythromycin and $100 \mu \mathrm{g} / \mathrm{ml}$ kanamycin. Integration by homologous recombination into the $\operatorname{ltg} A$ gene on the meningococcal chromosome was further monitored by PCR analysis using the oligonucleotides pilE1, NMF1, NMR1 and NMF1/NMR1. One transformant from each transformation was selected for further analysis and named $\Delta \operatorname{ltg} A^{\operatorname{ltg} A}$ or $\Delta \operatorname{ltg} A^{\operatorname{ltg} A \Delta 30}$. The strain $\Delta \operatorname{ltg} A^{\operatorname{ltg} A}$ has the $\operatorname{ltg} A$ gene deleted from its locus but harbors the $\operatorname{ltg} A$ gene downstream of the pilE site. The $\Delta \operatorname{ltg} A^{\operatorname{ltg} A \triangle 30}$ strain also has the $\operatorname{ltg} A$ gene deleted from its locus and contains a downstream pilE gene but harbors the $\lg A$ gene with the region encoding the amino acid residues 501-516 deleted.

\section{Coimmunoprecipitation studies}


Coimmunoprecipitation (IP) studies were carried out with lysates prepared from the $N$.

meningitidis MC58 strain. Harvested cells were washed in ice-cold 1× PBS. Cells were lysed in a solution containing $20 \mathrm{mM}$ Tris (pH 8), 137 mM sodium chloride, 1\% Nonidet P-40 (NP-40) detergent, $1 \mathrm{mM}$ EDTA and protease inhibitor cocktail (1 tablet/20 ml) to obtain approximately $1 \times 10^{7}$ cells per ml. Cells were incubated for $2 \mathrm{~h}$ at $4^{\circ} \mathrm{C}$ and then microcentrifuged for $15 \mathrm{~min}$ at $12,000 \mathrm{rpm}$. The supernatant was carefully removed into a fresh tube and kept on ice. The lysate was then precleared to prevent nonspecific binding to the beads. Briefly, $100 \mu$ of freshly prepared protein A sepharose beads was incubated with $1 \mathrm{ml}$ of lysate for $2 \mathrm{~h}$ at $4^{\circ} \mathrm{C}$ with gentle agitation. This slurry was then centrifuged for $10 \mathrm{~min}$ at $14,000 \times g$. Pelleted beads were discarded, and the supernatant was recovered. In a microcentrifuge tube, $50 \mu \mathrm{g}$ of the lysate was incubated overnight with $5 \mu \mathrm{l}$ of a polyclonal antiserum to $\operatorname{Ltg} \mathrm{A}$ at $4^{\circ} \mathrm{C}$ under gentle agitation. Seventy microliters of beads was added to each sample and incubated at $4^{\circ} \mathrm{C}$ for $4 \mathrm{~h}$. Samples were then centrifuged at 14,000 rpm, and the supernatant was discarded. The beads were then gently washed by centrifugation at $4{ }^{\circ} \mathrm{C}$ in lysis buffer three times to eliminate nonspecific binding. Fifty microliters of the sample was heated at $90^{\circ} \mathrm{C}$ for $5 \mathrm{~min}$ in $2 \times$ loading buffer, loaded onto an SDS gel and analyzed by western blotting.

\section{Immunoprecipitation and LC-MS/MS analysis}

For immunoprecipitation of $\operatorname{Ltg} \mathrm{A}$ from $\Delta \operatorname{ltg} A^{\operatorname{ltg} A}, \Delta \operatorname{ltg} A^{\operatorname{ltg} A \Delta 30}$, and $\Delta \operatorname{ltg} A$, beads were washed 4 times with $1 \mathrm{ml}$ of ice-cold PBS and 4 times with $1 \mathrm{ml}$ of ice-cold digestion buffer (20 $\mathrm{mM}$ Tris ( $\mathrm{pH} 8.0$ ), $2 \mathrm{mM} \mathrm{CaCl}_{2}$ ). The washed beads were resuspended in $200 \mu 1$ of digestion buffer and incubated for $5 \mathrm{~h}$ with $1 \mu \mathrm{g}$ of trypsin (Promega) at $37^{\circ} \mathrm{C}$. The beads were removed, an additional $1 \mu \mathrm{g}$ of trypsin was added, and the proteins were further digested overnight at $37^{\circ} \mathrm{C}$. Peptides were purified by OMIX C18 tips (Agilent), dried and redissolved in $30 \mu 1$ of $0.1 \%$ formic acid in water/acetonitrile (98:2, v/v), of which $1 \mu 1$ was injected for LC-MS/MS analysis on an EASY-nLC 1000 system (Proxeon, Thermo Fisher Scientific) connected in line to a Q Exactive Plus mass spectrometer with a Nanospray Flex ion source (Thermo Fisher Scientific). Peptides were loaded in solvent A ( $0.1 \%$ formic acid in water) on a reversed-phase column (made in-house, $75 \mu \mathrm{m}$ i.d. $\times 500 \mathrm{~mm}, 1.9 \mu \mathrm{m}$ beads, C18 Reprosil-Pur Dr. Maisch) and eluted by increasing solvent B (0.1\% formic acid in acetonitrile) in linear gradients from $5 \%$ to $27 \%$ in 100 min, then from $27 \%$ to $45 \%$ in $40 \mathrm{~min}$, and finally from $45 \%$ to $60 \%$ in $10 \mathrm{~min}$, all at a constant flow rate of $250 \mathrm{nl} / \mathrm{min}$. The mass spectrometer was operated in data-dependent mode, automatically switching between MS and MS/MS acquisition for the five most abundant ion peaks per MS spectrum. Full-scan MS spectra $(300-1700 \mathrm{~m} / \mathrm{z})$ were acquired at a resolution of 
70,000 after accumulation to a target value of 3,000,000 with a maximum fill time of $20 \mathrm{~ms}$. The five most intense ions above a threshold value of 170,000 were isolated (window of $1.6 \mathrm{Th}$ ) for fragmentation at a normalized collision energy of $27 \%$ after filling the trap at a target value of $1,000,000$ for a maximum of $60 \mathrm{~ms}$ with an underfill ratio of $1 \%$. The S-lens RF level was set at 60 , and we excluded precursor ions with single, unassigned and charged states greater than six from fragmentation selection.

\section{Fluorescent labeling and fluorescent microscopy}

Bacterial cultures were centrifuged 5 minutes at $5000 \mathrm{rpm}$ and re-suspended in PBS containing $1 \mu \mathrm{g} / \mathrm{mL}$ DAPI and 5 $\mu \mathrm{g} / \mathrm{ml}$ FM4-64 FX ( $N$-(3-Triethylammoniumpropyl)-4-(6-(4 (Diethylamino) Phenyl) Hexatrienyl) Pyridinium Dibromide) probe. The cells were incubated for 10 minutes at room temperature protected from light, centrifuged and the pellets resuspended in $4 \% \mathrm{pFA}$ for fixation during 5 minutes. After fixation, the cells were washed with PBS, and a 10 $\mu \mathrm{L}$ drop of the bacterial suspension was applied onto poly-Lysine pre-coated cover glasses (\# 1.5). Next, samples were mounted using Prolong Diamond and imaged using Leica SP5 confocal microscope, with a $63 \mathrm{X}$ (1.4 NA) oil-immersion objective using $405 \mathrm{~nm}$ and $514 \mathrm{~nm}$ laser lines. Fluorescence was recorded sequentially using hybrid (HyD) detectors and images processed using $\mathrm{Fiji}^{72}$.

\section{Scanning electron microscopy}

Neisseria meningitidis were prefixed in 2.5\% Glutaraldehyde diluted in PHEM (Pipes, Hepes, EGTA and $\mathrm{MgSO}_{4}$ ) buffer at $\mathrm{pH}$ 7. The cells were prefixed for $1 \mathrm{hr}$ at room temperature, followed by 2 washes in PHEM buffer. The samples were applied onto the cover glass $(1.5 \mathrm{~mm})$ pre-coated with poly-Lysine. This was followed by a light speed centrifugation to ensure that the cells adhere correctly to the cover slip.

The bacteria were post-fixed using 2\% osmium tetroxide in PHEM buffer for 30 to 60 minutes followed by washing with water three times. The specimen was dehydrated using increasing ethanol concentrations of $25 \%$ to $100 \%$ in increments of $25 \%$. The bacteria were critically point dried using carbon dioxide, coated with gold and examined with the JEOL JSM-

6700F scanning electron microscope.

\section{Protein identification and quantification}


Data analysis was performed with MaxQuant (version 1.6.3.4) ${ }^{73}$ using the Andromeda search engine with the default search settings, including a false discovery rate of $1 \%$ at both the peptide and protein levels. Spectra were searched against a database of 2204 proteins from $N$. meningitidis strain 8013 (taxid 604162, downloaded from http://www.ncbi.nlm.nih.gov/). The mass tolerance for precursor and fragment ions was set to 4.5 and $20 \mathrm{ppm}$, respectively, during the main search. Enzyme specificity was set as C-terminal to arginine and lysine, also allowing cleavage at proline bonds, with a maximum of two missed cleavages. Variable modifications were set to oxidation of methionine residues. Only proteins with at least one unique or razor peptide were retained, leading to the identification of 879 Neisseria proteins. Proteins were quantified by the MaxLFQ algorithm integrated in MaxQuant software ${ }^{74}$. A minimum ratio count of two unique or razor peptides was required for quantification. Further data analysis was performed with Perseus software (version 1.5.2.4) after loading the protein group file from MaxQuant LFQ intensity values were $\log 2$ transformed and replicate samples of the three strains were grouped. Proteins with less than three valid values in at least one group were removed, and missing values were imputed from a normal distribution around the detection limit. Then, $\mathrm{t}$-tests were performed $(\mathrm{FDR}=0.05$ and $\mathrm{S} 0=1)$ for pairwise comparisons of $\Delta \operatorname{ltg} A^{\operatorname{ltg} A}$ with $\triangle \operatorname{ltg} A$ and $\Delta \operatorname{ltg} A^{\operatorname{ltg} A \Delta 30}$ with $\Delta \operatorname{ltg} \mathrm{A}$. The results of these t-tests are listed in Supplementary Table 2.

\section{$O$-acetyl peptidoglycan esterase assay}

The acetyl esterase activity assays were executed as previously described with minor modifications $^{42,75}$. Briefly, the reaction utilized $2 \mathrm{mM} 4$-nitrophenyl acetate as the substrate. The reaction was carried out at $37{ }^{\circ} \mathrm{C}$ in $50 \mathrm{mM}$ sodium phosphate buffer, $\mathrm{pH} 6.5$ in the presence of LtgA, using equimolar amounts of LtgA and Ape1 or Ape1. The final volume of the reaction was $300 \mu$ l. The reaction was initiated with the addition of the substrate 4-nitrophenyl acetate dissolved in 5\% v/v ethanol. The release of 4-nitrophenyl was monitored over the time course of an hour in 96 well microtiter plate at an absorbance of $405 \mathrm{~nm}$.

\section{Analysis of LtgA activity}

To assess the activity of $\operatorname{Ltg} A, P G(200 \mu \mathrm{g})$ was incubated in the presence of $\operatorname{Ltg} \mathrm{A}$, or equimolar amounts of LtgA and Ape1, in $12.5 \mathrm{mM}$ sodium phosphate buffer pH 5.6. Neisseria PG was purified as previously described ${ }^{76}$. The reaction mix was initiated by the addition of enzymes and incubated at $37^{\circ} \mathrm{C}$ for $5 \mathrm{~min}$. Control reactions lacking PG or enzyme/inhibitor were also included. The final reaction volume was $200 \mu \mathrm{L}$. Reactions were performed in triplicates. The reaction was stopped by incubating the samples in a heat block at $100{ }^{\circ} \mathrm{C}$ for $5 \mathrm{~min}$. The 
soluble 1,6-anhydro-muropeptides was collected using centrifugation at $16,000 \mathrm{~g}$ for $10 \mathrm{~min}$ at room temperature. The supernatant was collected and analyzed by reversed-phase HPLC using a Shimadzu LC-20 system with a Hypersil GOLD aQ column ( $5 \mu \mathrm{m}$ particle size, $250 \times 4.6 \mathrm{~mm}$, flow rate $0.5 \mathrm{~mL} / \mathrm{mL}$ at $52{ }^{\circ} \mathrm{C}$; Thermo Fisher Scientific (Waltham, MA, USA). The mobile phase gradient was $50 \mathrm{mM}$ sodium phosphate $\mathrm{pH} 4.3$ to $75 \mathrm{mM}$ sodium phosphate $\mathrm{pH} 4.9$ with $15 \%$ Methanol over 135 min.

\section{Infection model}

A previously published model for meningococcal infection in transgenic mice expressing human transferrin was used ${ }^{77}$. Four strains were tested: clone 12 (wild-type), $\operatorname{ltg} A^{\lg A}$, $\Delta \operatorname{ltg} A^{\operatorname{ltg} A \Delta 30}$ and $\triangle \operatorname{ltg} A$. Five mice per group were infected by intraperitoneal injection with $500 \mu 1$ of bacterial suspension of each strain at $1 \times 10^{7} \mathrm{CFU} / \mathrm{ml}$. Blood samples were obtained by retroorbital bleeding after 2, 6 and $24 \mathrm{~h}$, and bacterial counts were determined by plating serial dilutions on GCB medium.

\section{Phylogenetic tree construction}

Protein sequences were aligned using MUSCLE alignment algorithm using UPGMA clustering method in MEGAX ${ }^{78}$. Using aligned sequences, a maximum likelihood tree was constructed using a Neighbor joining construction method and a JTT protein substitution model in CLC Genomics Workbench 8.01. Robustness was estimated using 500 bootstrap replicates (values not shown in figures).

\section{Ethics Statement}

Animal work in this study was carried out at the Institut Pasteur in strict accordance with the European Union Directive 2010/63/EU (and its revision 86/609/EEC) on the protection of animals used for scientific purposes. The laboratory at the Institut Pasteur has the administrative authorization for animal experimentation (Permit Number 75-1554) and the protocol was approved by the Institut Pasteur Review Board that is part of the Regional Committee of Ethics of Animal Experiments of Paris Region (Permit Number: 99-174). All the invasive procedures were performed under anesthesia and all possible efforts were made to minimize animal suffering.

\section{Cytokine assay}


Blood samples from infected mice were collected and stored at $-80^{\circ} \mathrm{C}$. Cytokines (IL-6 and $\mathrm{KC}$ ) were quantified by an enzyme-linked immunosorbent assay (Quantikine; R\&D Systems Europe, Abingdon, Oxon, United Kingdom).

\section{Growth curves and LtgA stability assay}

Bacteria were grown overnight in GC broth with Kellogg's supplements at $37^{\circ} \mathrm{C}$ and $5 \%$ $\mathrm{CO}_{2}$. Fresh medium was inoculated at an OD600 of 0.05, and growth was measured spectrophotometrically at 1 -h intervals over a period of $24 \mathrm{~h}$ at $37^{\circ} \mathrm{C}$ and $5 \% \mathrm{CO}_{2}$. When indicated, $2 \mu \mathrm{g} / \mathrm{ml}$ chloramphenicol was added when the $\mathrm{OD}_{600}$ reached 0.6 , and incubation was continued at $37^{\circ} \mathrm{C}$ and $5 \% \mathrm{CO}_{2}$. At different incubation time points, aliquots $(3 \mathrm{ml})$ from each culture were sampled, and the bacteria were collected by centrifugation, lysed by boiling in SDScontaining sample buffer, and analyzed for the presence of LtgA by western blotting using antiLtgA antibodies. The expression of the outer membrane factor $\mathrm{H}$ binding protein (Fhbp) was used as an internal control.

\section{PG binding assay}

The binding of the different LtgA proteins to PG was carried out by incubating $100 \mu \mathrm{g}$ of PG and $10 \mu \mathrm{g}$ of enzymes suspended in $150 \mu \mathrm{l}$ of Tris buffer $\mathrm{pH} 7.5(10 \mathrm{mM}$ Tris, $10 \mathrm{mM} \mathrm{MgCl} 2$ and $50 \mathrm{mM} \mathrm{NaCl}$ ). After $30 \mathrm{~min}$ of rocking at room temperature, $50 \mu \mathrm{l}$ of the sample was set aside for analysis before centrifugation for $10 \mathrm{~min}$ at 20,000 $\mathrm{xg}$. The supernatant was discarded, and the insoluble fraction was washed three times. The remaining pellet was boiled for $10 \mathrm{~min}$. Five microliters of the input or unbound and bound fractions was loaded on an SDS-PAGE gel and analyzed by western blotting.

\section{Accession numbers}

Coordinates and structural data have been submitted to the Protein Data Bank under the accession code $6 \mathrm{H} 5 \mathrm{~F}$. The mass spectrometry proteomics data have been deposited to the ProteomeXchange Consortium via the PRIDE partner repository with the dataset identifier PXD013393 (reviewer login: reviewer83496@ebi.ac.uk; password: mkJ4Yxxn).

\section{Acknowledgments}

We would like to acknowledge the beamline staff (PROXIMA-1 at SOLEIL and X06DA at SLS) for their assistance. We are extremely grateful to Frederick Saul, Patrick Weber and Marco Bellinzoni for their constant helpful guidance, advice and assistance. We thank Dr. Antoine 
820 Forget for the advice on and help with figure presentations. A.H.W. was supported by an EMBO

821 long-term fellowship (ALTF 732-2010) and an Institut Carnot-Pasteur Maladies Infectious

822 fellowship. This work was supported by an ERC starting grant (PGN from SHAPE to VIR

823 202283) and a Fondation pour la recherche médicale (FRM) grant Programme d'Urgence

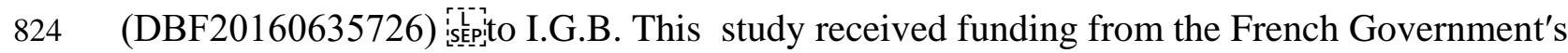

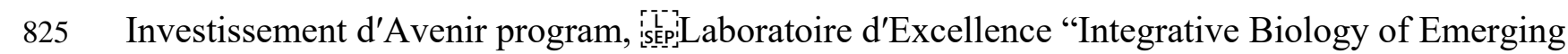

826 Infectious Diseases" (grant nANR- iscepi 10-LABX-62-IBEID). F.I. was supported by a Pasteur

827 Roux fellowship P.A.D.B. is supported by the European Union's Horizon 2020 research and

828 innovation program under the Marie Sklodowska-Curie grant agreement $\mathrm{N}^{\mathrm{o}} 665807$ and by the

829 Institut Carnot Pasteur Microbes \& Santé. IS was supported by the Institut Carnot Pasteur

830 Microbes \& Santé given to the Pasteur-Paris University PhD program and the "Fin de these de

831 science" number FDT201805005258 granted by "Fondation pour la recherche médicale (FRM).

Contributions

834 A.H.W. and I.G.B. designed the research. A.H.W. purified and biochemically characterized the protein. R.W. and A.H.W. conducted the HPLC-based enzyme assays. A.H.W. and A.H. conducted all the structural experiments. A.H. collected the X-ray data. A.H.W. solved and refined all the structures. M-K.T., A.E.D, I.S. conducted biological validation of the structural studies. F.I., C.M.J.C-R, P.B. conducted mass spectrometric analysis. A.H.W., R.W., I.G.B., analyzed the data. W.A.H.W. wrote the manuscript. I.S., R.W., I.G.B., A.H., M-K.T contributed to the editing of the article. 


\section{References}

1 Williams, A. H. et al. A step-by-step in crystallo guide to bond cleavage and 1,6-anhydrosugar product synthesis by a peptidoglycan-degrading lytic transglycosylase. J Biol Chem 293, 6000-6010, doi:10.1074/jbc.RA117.001095 (2018).

2 Viala, J. et al. Nod1 responds to peptidoglycan delivered by the Helicobacter pylori cag pathogenicity island. Nature immunology 5, 1166-1174, doi:10.1038/ni1131 (2004).

3 Blackburn, N. T. \& Clarke, A. J. Identification of four families of peptidoglycan lytic transglycosylases. J. Mol. Evol. 52, 78-84 (2001).

4 Williams, A. H. et al. Bulgecin A: The key to a broad-spectrum inhibitor that targets lytic transglycosylases. Antibiotics (Basel) 6, 8, doi:10.3390/antibiotics6010008 (2017).

$5 \quad$ Williams, A. H. et al. A step-by-step in crystallo guide to bond cleavage and 1,6-anhydrosugar product synthesis by a peptidoglycan-degrading lytic transglycosylase. J. Biol. Chem. 293, 6000-6010, doi:10.1074/jbc.RA117.001095 (2018).

6 Vollmer, W., Joris, B., Charlier, P. \& Foster, S. Bacterial peptidoglycan (murein) hydrolases. FEMS microbiology reviews 32, 259-286, doi:10.1111/j.15746976.2007.00099.x (2008).

7 Thunnissen, A. M. et al. Doughnut-shaped structure of a bacterial muramidase revealed by X-ray crystallography. Nature 367, 750-753, doi:10.1038/367750a0 (1994).

8 van Asselt, E. J., Thunnissen, A. M. \& Dijkstra, B. W. High resolution crystal structures of the Escherichia coli lytic transglycosylase Slt70 and its complex with a peptidoglycan fragment. Journal of molecular biology 291, 877-898, doi:10.1006/jmbi.1999.3013 (1999).

9 Scheurwater, E., Reid, C. W. \& Clarke, A. J. Lytic transglycosylases: bacterial spacemaking autolysins. The international journal of biochemistry \& cell biology 40, 586-591, doi:10.1016/j.biocel.2007.03.018 (2008).

10 Reid, C. W., Blackburn, N. T., Legaree, B. A., Auzanneau, F. I. \& Clarke, A. J. Inhibition of membrane-bound lytic transglycosylase B by NAG-thiazoline. FEBS letters 574, 73-79, doi:10.1016/j.febslet.2004.08.006 (2004).

11 van Asselt, E. J. \& Dijkstra, B. W. Binding of calcium in the EF-hand of Escherichia coli lytic transglycosylase Slt35 is important for stability. FEBS letters 458, 429-435 (1999).

12 van Heijenoort, J. Peptidoglycan hydrolases of Escherichia coli. Microbiology and molecular biology reviews : MMBR 75, 636-663, doi:10.1128/MMBR.00022-11 (2011).

13 Heidrich, C., Ursinus, A., Berger, J., Schwarz, H. \& Holtje, J. V. Effects of multiple deletions of murein hydrolases on viability, septum cleavage, and sensitivity to large toxic molecules in Escherichia coli. J. Bacteriol. 184, 6093-6099 (2002).

14 Schaub, R. E. et al. Lytic transglycosylases LtgA and LtgD perform distinct roles in remodeling, recycling and releasing peptidoglycan in Neisseria gonorrhoeae. Mol Microbiol, doi:10.1111/mmi.13496 (2016).

15 Templin, M. F., Edwards, D. H. \& Holtje, J. V. A murein hydrolase is the specific target of bulgecin in Escherichia coli. J. Biol. Chem. 267, 20039-20043 (1992).

16 Tomoshige, S. et al. Total syntheses of bulgecins A, B, and C and their bactericidal potentiation of the beta-lactam antibiotics. ACS Infect. Dis., doi:10.1021/acsinfecdis.8b00105 (2018).

17 Weadge, J. T., Pfeffer, J. M. \& Clarke, A. J. Identification of a new family of enzymes with potential O-acetylpeptidoglycan esterase activity in both Gram-positive and Gramnegative bacteria. BMC microbiology 5, 49, doi:10.1186/1471-2180-5-49 (2005).

18 Diacovich, L. \& Gorvel, J. P. Bacterial manipulation of innate immunity to promote infection. Nature reviews. Microbiology 8, 117-128, doi:10.1038/nrmicro2295 (2010). 
19 Aubry, C. et al. OatA, a peptidoglycan O-acetyltransferase involved in Listeria monocytogenes immune escape, is critical for virulence. The Journal of infectious diseases 204, 731-740, doi:10.1093/infdis/jir396 (2011).

20 Clarke, C. A., Scheurwater, E. M. \& Clarke, A. J. The vertebrate lysozyme inhibitor Ivy functions to inhibit the activity of lytic transglycosylase. J Biol Chem 285, 14843-14847, doi:10.1074/jbc.C110.120931 (2010).

21 Bera, A., Herbert, S., Jakob, A., Vollmer, W. \& Gotz, F. Why are pathogenic staphylococci so lysozyme resistant? The peptidoglycan O-acetyltransferase OatA is the major determinant for lysozyme resistance of Staphylococcus aureus. Molecular microbiology 55, 778-787, doi:10.1111/j.1365-2958.2004.04446.x (2005).

22 Weadge, J. T. \& Clarke, A. J. Identification and characterization of O-acetylpeptidoglycan esterase: a novel enzyme discovered in Neisseria gonorrhoeae. Biochemistry 45, 839-851, doi:10.1021/bi051679s (2006).

23 Pfeffer, J. M. \& Clarke, A. J. Identification of the first known inhibitors of Oacetylpeptidoglycan esterase: a potential new antibacterial target. Chembiochem : a European journal of chemical biology 13, 722-731, doi:10.1002/cbic.201100744 (2012).

24 Dijkstra, B. W. \& Thunnissen, A. M. 'Holy' proteins. II: The soluble lytic transglycosylase. Current opinion in structural biology 4, 810-813 (1994).

25 Romeis, T. \& Holtje, J. V. Specific interaction of penicillin-binding proteins 3 and 7/8 with soluble lytic transglycosylase in Escherichia coli. J. Biol. Chem. 269, 21603-21607 (1994).

26 Legaree, B. A. \& Clarke, A. J. Interaction of penicillin-binding protein 2 with soluble lytic transglycosylase B1 in Pseudomonas aeruginosa. J. Bacteriol. 190, 6922-6926, doi:10.1128/JB.00934-08 (2008).

27 Vollmer, W. \& Bertsche, U. Murein (peptidoglycan) structure, architecture and biosynthesis in Escherichia coli. Biochimica et biophysica acta 1778, 1714-1734, doi:10.1016/j.bbamem.2007.06.007 (2008).

28 von Rechenberg, M., Ursinus, A. \& Holtje, J. V. Affinity chromatography as a means to study multienzyme complexes involved in murein synthesis. Microb. Drug Resist. 2, 155157 (1996).

29 Cho, H. et al. Bacterial cell wall biogenesis is mediated by SEDS and PBP polymerase families functioning semi-autonomously. Nat. Microbiol. 1, 16172, doi:10.1038/nmicrobiol.2016.172 (2016).

30 Meeske, A. J. et al. SEDS proteins are a widespread family of bacterial cell wall polymerases. Nature 537, 634-638, doi:10.1038/nature19331 (2016).

31 Sjodt, M. et al. Structure of the peptidoglycan polymerase RodA resolved by evolutionary coupling analysis. Nature 556, 118-121, doi:10.1038/nature25985 (2018).

32 Sauvage, E., Kerff, F., Terrak, M., Ayala, J. A. \& Charlier, P. The penicillin-binding proteins: structure and role in peptidoglycan biosynthesis. FEMS microbiology reviews $\mathbf{3 2}$, 234-258, doi:10.1111/j.1574-6976.2008.00105.x (2008).

33 Zarantonelli, M. L. et al. Penicillin resistance compromises Nod1-dependent proinflammatory activity and virulence fitness of neisseria meningitidis. Cell Host Microbe 13, 735-745, doi:10.1016/j.chom.2013.04.016 (2013).

34 Leclercq, S. et al. Interplay between Penicillin-binding proteins and SEDS proteins promotes bacterial cell wall synthesis. Sci. Rep. 7, 43306, doi:10.1038/srep43306 (2017).

35 Taguchi, A. et al. FtsW is a peptidoglycan polymerase that is activated by its cognate penicillin-binding protein. bioRxiv, 358663, doi:10.1101/358663 (2018).

36 Bonis, M., Williams, A., Guadagnini, S., Werts, C. \& Boneca, I. G. The effect of bulgecin A on peptidoglycan metabolism and physiology of Helicobacter pylori. Microb. Drug Resist. 18, 230-239, doi:10.1089/mdr.2011.0231 (2012). 
37 Artola-Recolons, C. et al. High-resolution crystal structure of MltE, an outer membraneanchored endolytic peptidoglycan lytic transglycosylase from Escherichia coli. Biochemistry 50, 2384-2386, doi:10.1021/bi200085y (2011).

38 Fibriansah, G., Gliubich, F. I. \& Thunnissen, A. M. On the mechanism of peptidoglycan binding and cleavage by the endo-specific lytic transglycosylase MltE from Escherichia coli. Biochemistry 51, 9164-9177, doi:10.1021/bi300900t (2012).

39 Artola-Recolons, C. et al. Structure and cell wall cleavage by modular lytic transglycosylase MltC of Escherichia coli. ACS chemical biology 9, 2058-2066, doi:10.1021/cb500439c (2014).

40 Holtje, J. V. Lytic transglycosylases. EXS 75, 425-429 (1996).

41 Chan, Y. A., Hackett, K. T. \& Dillard, J. P. The lytic transglycosylases of Neisseria gonorrhoeae. Microb. Drug Resist. 18, 271-279, doi:10.1089/mdr.2012.0001 (2012).

42 Pfeffer, J. M., Weadge, J. T. \& Clarke, A. J. Mechanism of Action of Neisseria gonorrhoeae O-Acetylpeptidoglycan Esterase, an SGNH Serine Esterase. J Biol Chem 288, 2605-2613, doi:10.1074/jbc.M112.436352 (2013).

43 Weadge, J. T. \& Clarke, A. J. Neisseria gonorrheae O-acetylpeptidoglycan esterase, a serine esterase with a Ser-His-Asp catalytic triad. Biochemistry 46, 4932-4941, doi:10.1021/bi700254m (2007).

44 Veyrier, F. J. et al. De-O-acetylation of peptidoglycan regulates glycan chain extension and affects in vivo survival of Neisseria meningitidis. Mol Microbiol 87, 1100-1112, doi:10.1111/mmi.12153 (2013).

45 Cloud, K. A. \& Dillard, J. P. A lytic transglycosylase of Neisseria gonorrhoeae is involved in peptidoglycan-derived cytotoxin production. Infection and immunity 70, 2752-2757 (2002).

46 Cloud, K. A. \& Dillard, J. P. Mutation of a single lytic transglycosylase causes aberrant septation and inhibits cell separation of Neisseria gonorrhoeae. J. Bacteriol. 186, 78117814, doi:10.1128/JB.186.22.7811-7814.2004 (2004).

47 Girardin, S. E. et al. Nod2 is a general sensor of peptidoglycan through muramyl dipeptide (MDP) detection. J. Biol. Chem. 278, 8869-8872, doi:10.1074/jbc.C200651200 (2003).

48 Schaub, R. E. et al. Lytic transglycosylases LtgA and LtgD perform distinct roles in remodeling, recycling and releasing peptidoglycan in Neisseria gonorrhoeae. Molecular microbiology 102, 865-881, doi:10.1111/mmi.13496 (2016).

49 Suay-Garcia, B. \& Perez-Gracia, M. T. Drug-resistant Neisseria gonorrhoeae: latest developments. Eur. J. Clin. Microbiol. Infect. Dis. 36, 1065-1071, doi:10.1007/s10096017-2931-x (2017).

50 Lee, M. et al. Reactions of all Escherichia coli lytic transglycosylases with bacterial cell wall. Journal of the American Chemical Society 135, 3311-3314, doi:10.1021/ja309036q (2013).

51 Cloud, K. A. \& Dillard, J. P. Mutation of a single lytic transglycosylase causes aberrant septation and inhibits cell separation of Neisseria gonorrhoeae. J Bacteriol 186, 78117814, doi:10.1128/JB.186.22.7811-7814.2004 (2004).

52 Muller, P. et al. The essential cell division protein FtsN interacts with the murein (peptidoglycan) synthase PBP1B in Escherichia coli. J. Biol. Chem. 282, 36394-36402, doi:10.1074/jbc.M706390200 (2007).

53 Peters, N. T., Dinh, T. \& Bernhardt, T. G. A fail-safe mechanism in the septal ring assembly pathway generated by the sequential recruitment of cell separation amidases and their activators. J. Bacteriol. 193, 4973-4983, doi:10.1128/JB.00316-11 (2011).

54 Bertsche, U. et al. Interaction between two murein (peptidoglycan) synthases, PBP3 and PBP1B, in Escherichia coli. Molecular microbiology 61, 675-690, doi:10.1111/j.13652958.2006.05280.x (2006). 
55 Ursinus, A. et al. Murein (peptidoglycan) binding property of the essential cell division protein FtsN from Escherichia coli. J. Bacteriol. 186, 6728-6737, doi:10.1128/JB.186.20.6728-6737.2004 (2004).

56 Tsang, M. J. \& Bernhardt, T. G. A role for the FtsQLB complex in cytokinetic ring activation revealed by an ftsL allele that accelerates division. Molecular microbiology $\mathbf{9 5}$, 925-944, doi:10.1111/mmi.12905 (2015).

57 Gerding, M. A. et al. Self-enhanced accumulation of FtsN at division sites and roles for other proteins with a SPOR domain (DamX, DedD, and RlpA) in Escherichia coli cell constriction. J. Bacteriol. 191, 7383-7401, doi:10.1128/JB.00811-09 (2009).

58 Yang, J. C., Van Den Ent, F., Neuhaus, D., Brevier, J. \& Lowe, J. Solution structure and domain architecture of the divisome protein FtsN. Molecular microbiology 52, 651-660, doi:10.1111/j.1365-2958.2004.03991.x (2004).

59 Cloud-Hansen, K. A., Hackett, K. T., Garcia, D. L. \& Dillard, J. P. Neisseria gonorrhoeae uses two lytic transglycosylases to produce cytotoxic peptidoglycan monomers. $J$ Bacteriol 190, 5989-5994, doi:10.1128/JB.00506-08 (2008).

60 Clarke, T. B. et al. Recognition of peptidoglycan from the microbiota by Nod1 enhances systemic innate immunity. Nat Med 16, 228-231, doi:10.1038/nm.2087 (2010).

61 Tourneur, E. et al. Cyclosporine A impairs nucleotide binding oligomerization domain (Nod1)-mediated innate antibacterial renal defenses in mice and human transplant recipients. PLoS Pathog 9, e1003152, doi:10.1371/journal.ppat.1003152 (2013).

62 Adams, P. D. et al. PHENIX: a comprehensive Python-based system for macromolecular structure solution. Acta crystallographica. Section D, Biological crystallography 66, 213221, doi:10.1107/S0907444909052925 (2010).

63 Emsley, P. \& Cowtan, K. Coot: model-building tools for molecular graphics. Acta crystallographica. Section D, Biological crystallography 60, 2126-2132, doi:10.1107/S0907444904019158 (2004).

64 Collaborative Computational Project. The CCP4 suite: programs for protein crystallography. Acta crystallographica. Section D, Biological crystallography 50, 760763, doi:10.1107/S0907444994003112 (1994).

65 Davis, I. W., Murray, L. W., Richardson, J. S. \& Richardson, D. C. MOLPROBITY: structure validation and all-atom contact analysis for nucleic acids and their complexes. Nucleic acids research 32, W615-619, doi:10.1093/nar/gkh398 (2004).

66 Kelley, L. A., Mezulis, S., Yates, C. M., Wass, M. N. \& Sternberg, M. J. The Phyre2 web portal for protein modeling, prediction and analysis. Nat Protoc 10, 845-858, doi:10.1038/nprot.2015.053 (2015).

67 Nassif, X. et al. Antigenic variation of pilin regulates adhesion of Neisseria meningitidis to human epithelial cells. Molecular microbiology 8, 719-725 (1993).

68 Tettelin, H. et al. Complete genome sequence of Neisseria meningitidis serogroup B strain MC58. Science 287, 1809-1815 (2000).

69 Kellogg, D. S., Jr., Peacock, W. L., Jr., Deacon, W. E., Brown, L. \& Pirkle, D. I. Neisseria gonorrhoeae. I. Virulence Genetically Linked to Clonal Variation. J. Bacteriol. 85, 12741279 (1963).

70 Hanahan, D. Studies on transformation of Escherichia coli with plasmids. Journal of molecular biology 166, 557-580 (1983).

71 Taha, M. K. et al. Pilus-mediated adhesion of Neisseria meningitidis: the essential role of cell contact-dependent transcriptional upregulation of the PilC1 protein. Molecular microbiology 28, 1153-1163 (1998).

72 Schindelin, J. et al. Fiji: an open-source platform for biological-image analysis. Nat Methods 9, 676-682, doi:10.1038/nmeth.2019 (2012). 
73 Cox, J. \& Mann, M. MaxQuant enables high peptide identification rates, individualized p.p.b.-range mass accuracies and proteome-wide protein quantification. Nat. Biotechnol. 26, 1367-1372 (2008).

74 Cox, J. et al. Accurate proteome-wide label-free quantification by delayed normalization and maximal peptide ratio extraction, termed MaxLFQ. Mol. Cell. Proteomics 13, 25132526 (2014).

75 Hadi, T., Pfeffer, J. M., Clarke, A. J. \& Tanner, M. E. Water-soluble substrates of the peptidoglycan-modifying enzyme O-acetylpeptidoglycan esterase (Ape1) from Neisseria gonorrheae. J Org Chem 76, 1118-1125, doi:10.1021/jo102329c (2011).

76 Wheeler, R., F. Veyrier, C. Werts, and I.G. Boneca, . in Glycoscience: Biology and Medicine Vol. 1 (ed N. Taniguchi, T. Endo, G.W. Hart, P.H. Seeberger, and C.-H. Wong,) 737-747 (Springer 2014).

77 Szatanik, M. et al. Experimental meningococcal sepsis in congenic transgenic mice expressing human transferrin. PLoS One 6, e22210 (2011).

78 Kumar, S., Stecher, G., Li, M., Knyaz, C. \& Tamura, K. MEGA X: Molecular Evolutionary Genetics Analysis across Computing Platforms. Mol Biol Evol 35, 15471549, doi:10.1093/molbev/msy096 (2018). 


\section{Supplemental Materials}

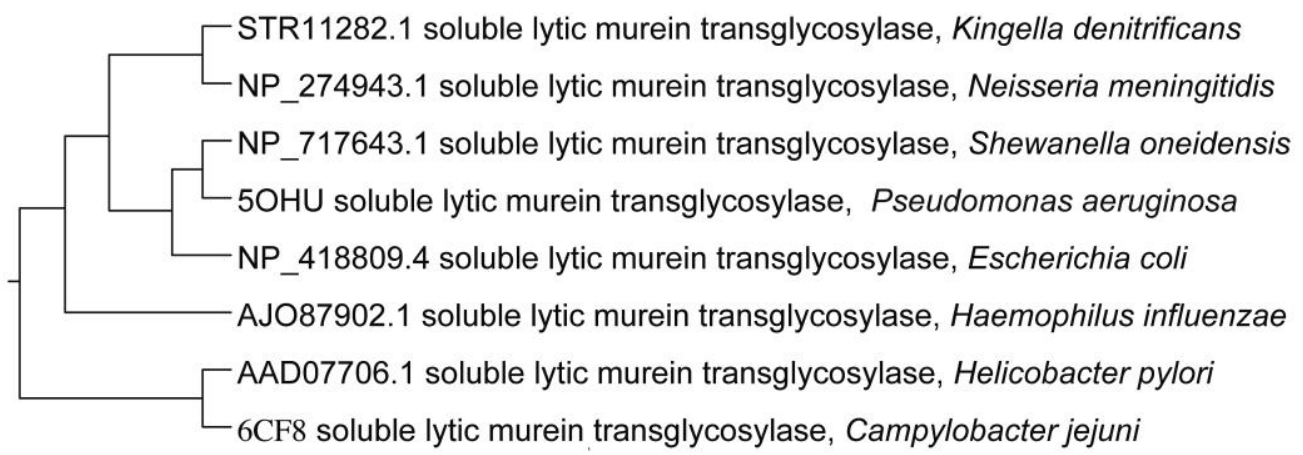

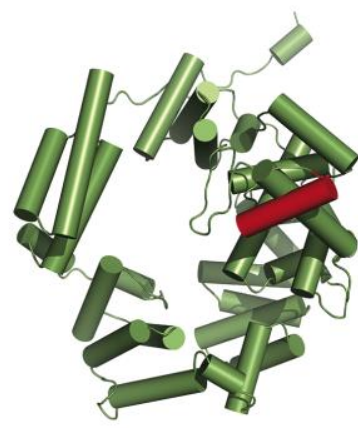

Neisseria meningitidis MC58 PDB ID: 6FPN

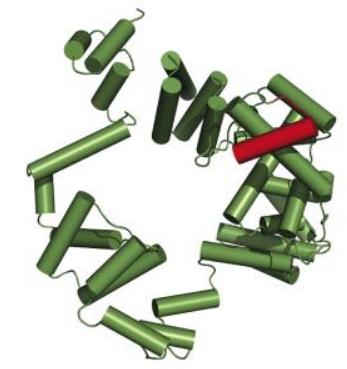

Pseudomonas aeruginosa PDB: $50 \mathrm{HU}$

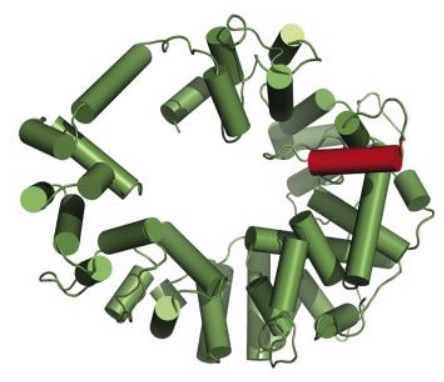

Helicobacter pylori 26695

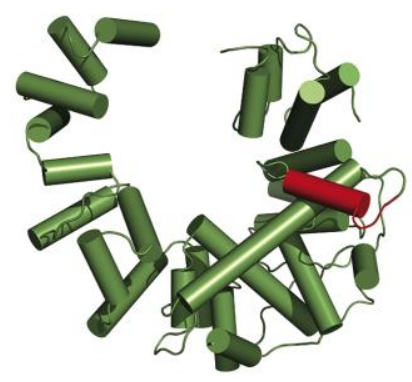

Campylobacter jejuni PDB ID: 6CF8

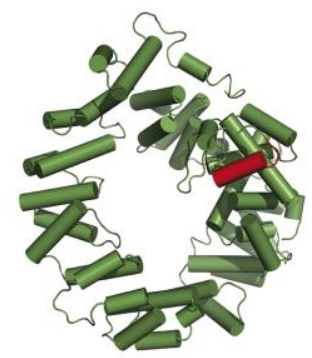

Escherichia coli PDB:1qsA

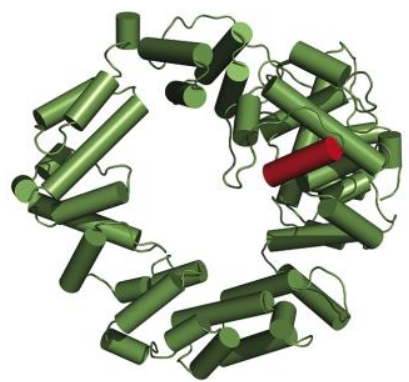

Haemophilus influenzae

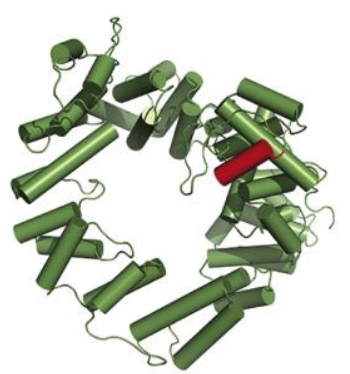

Kingella denitrificans

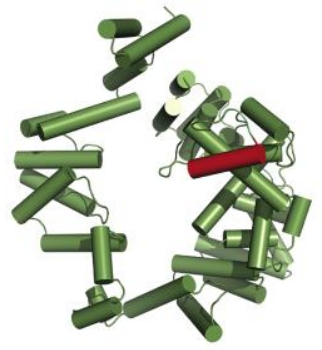

Shewanella Oneidensis

Supplementary Figure 1: Conservation of alpha helix 30 amongst diverse lytic complemented with various structures or predicted structures of lytic transglycosylases highlighing the conserved alpha helix 30 (PDB: protein data bank). 


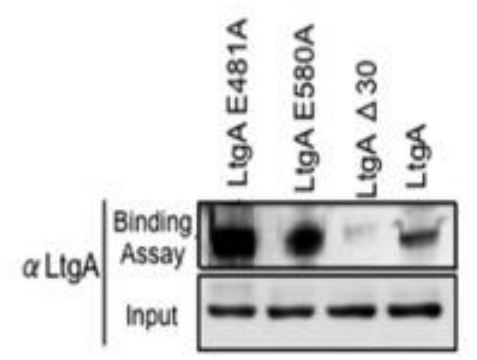

Supplementary Figure 2: Binding of LtgA to Peptidoglycan.

1100 Heterologously expressed purified proteins of LtgA E481, LtgA E508A, and LtgA ${ }^{\Delta 30}$ were tested 1101 for their ability to bind Neiserria PG. Equal concentrations of purified protein (5 $\mu \mathrm{g})$ were mixed 1102 with Neisseria PG and subjected to high-speed centrifugation. The western blot reflects proteins 1103 bound to insoluble PG. Comparatively, $\operatorname{Ltg} \mathrm{A}^{\Delta 30}$ appears to be defective in PG binding. 
bioRxiv preprint doi: https://doi.org/10.1101/607697; this version posted April 12, 2019. The copyright holder for this preprint (which was not certified by peer review) is the author/funder, who has granted bioRxiv a license to display the preprint in perpetuity. It is made available under aCC-BY 4.0 International license.

a)
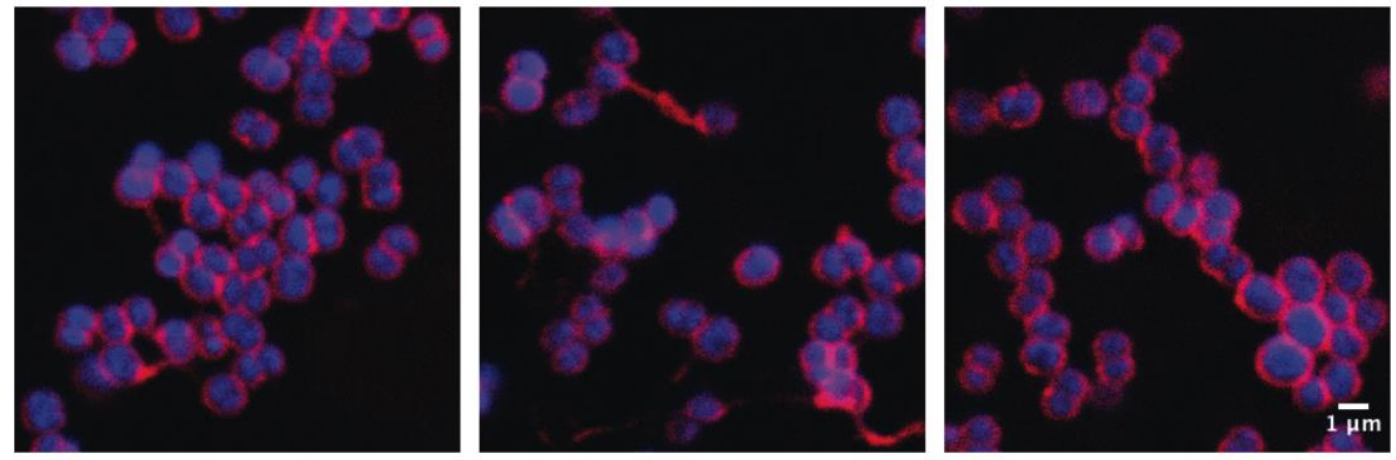

b)
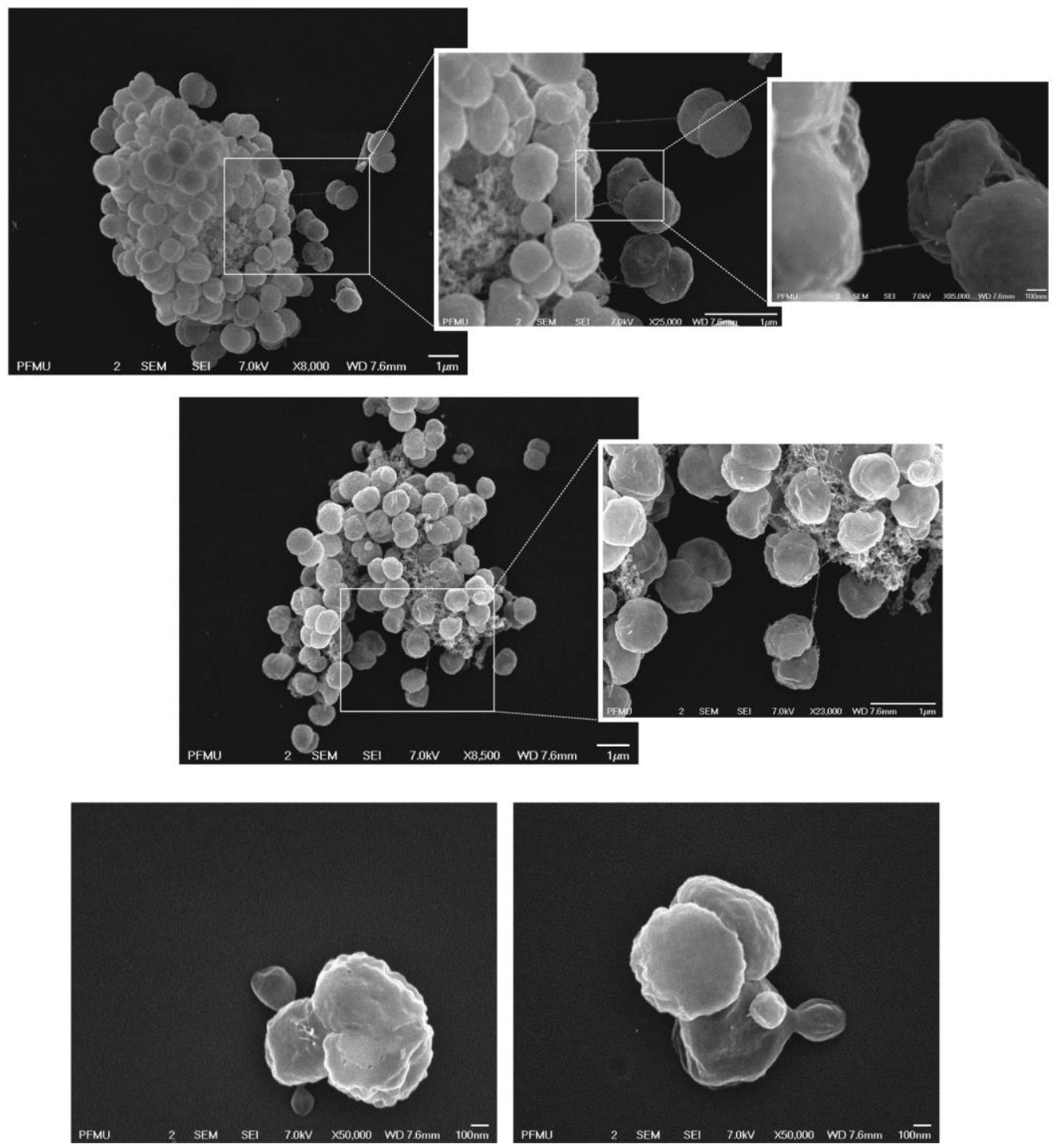


\section{Supplementary Figure 3. Morphological abnormalities of $\operatorname{LtgA}$ alpha helix 30 mutant.}

a) Fluorescent microscopy of $\Delta \lg A^{\operatorname{ltg} A \Delta 30}$ strain highlighting aggregated cells that are defective in division and separation. b) Scanning electron microscopy of $\Delta \operatorname{ltg} A^{\operatorname{ltg} A \Delta 30}$ strain detailing additional morphological abnormalities such as, aggregation of extracellular material that resembles type IV pilin protein structures that stretches between diplococcic bacteria.

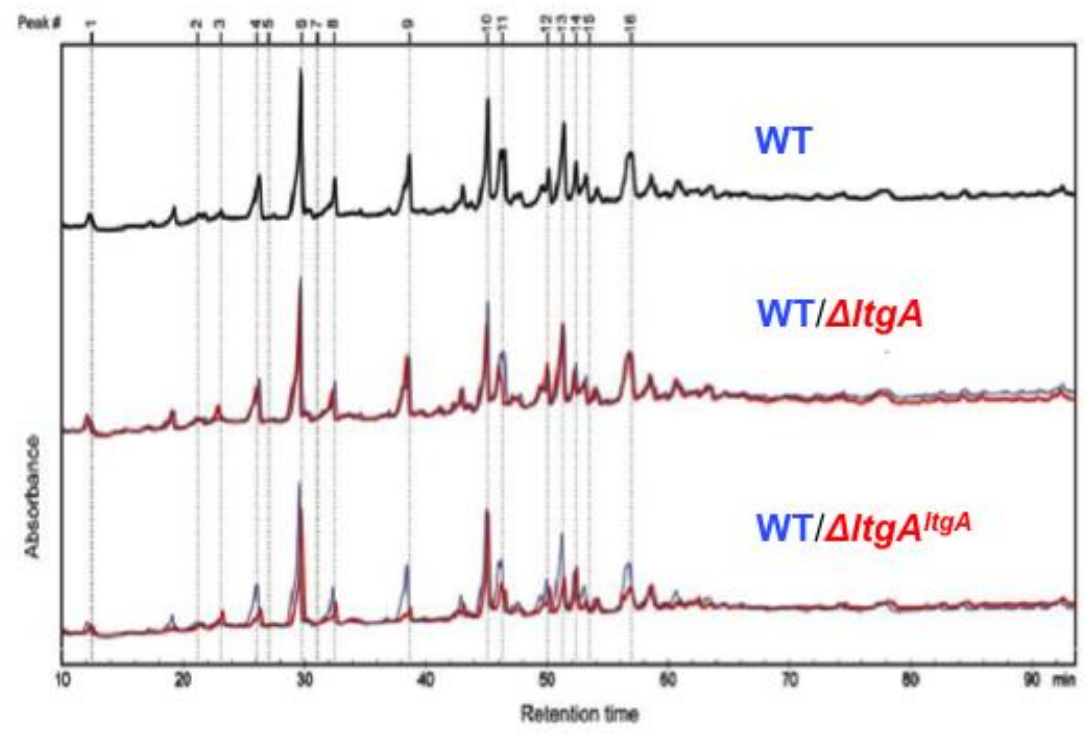

\section{Supplementary Figure 4. Muropeptide composition of PG isolated from wild-type, $\Delta \operatorname{ltg} A$,} muropeptides were reduced and then analyzed by LC/MS. The results were reproducible over 4 biological replicates. The wild-type chromatogram (blue) is overlaid on mutant chromatograms (red). Peak numbers correspond to Supplementary Table 1. 
bioRxiv preprint doi: https://doi.org/10.1101/607697; this version posted April 12, 2019. The copyright holder for this preprint (which was not certified by peer review) is the author/funder, who has granted bioRxiv a license to display the preprint in perpetuity. It is made available under aCC-BY 4.0 International license.

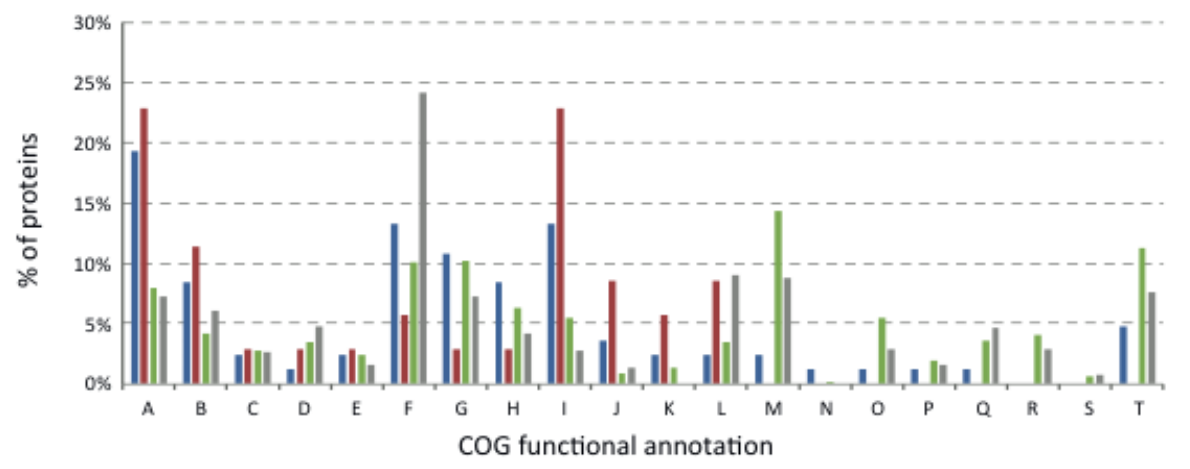

- proteins enriched in $\Delta / \operatorname{tg} A^{\lg _{g} A}$ strain

= all identified proteins

- proteins enriched in $\triangle \lg A^{\text {nga } \triangle 3^{0}}$ strain all Neisseria proteins
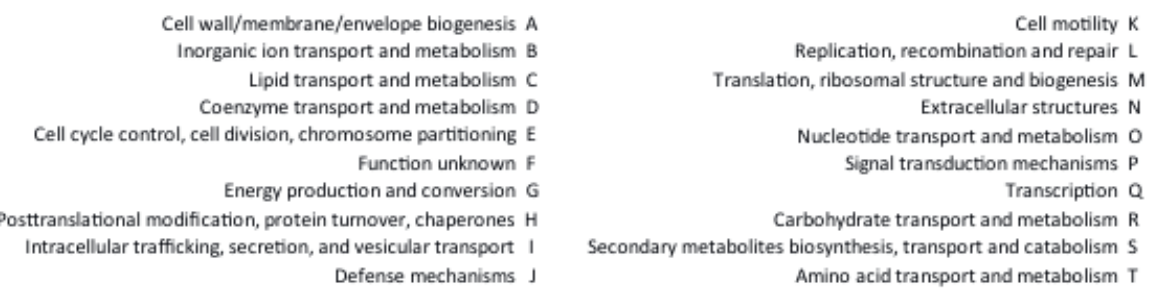

Supplementary Figure 5. Clusters of orthologous groups of proteins (COG) analysis showed that the PPI network for $\operatorname{Ltg} \mathrm{A}^{\Delta 30}$ mainly occurred in two functional categories: cell wall/membrane/envelope biogenesis and intracellular trafficking, secretion, and vesicular transport. 
a)
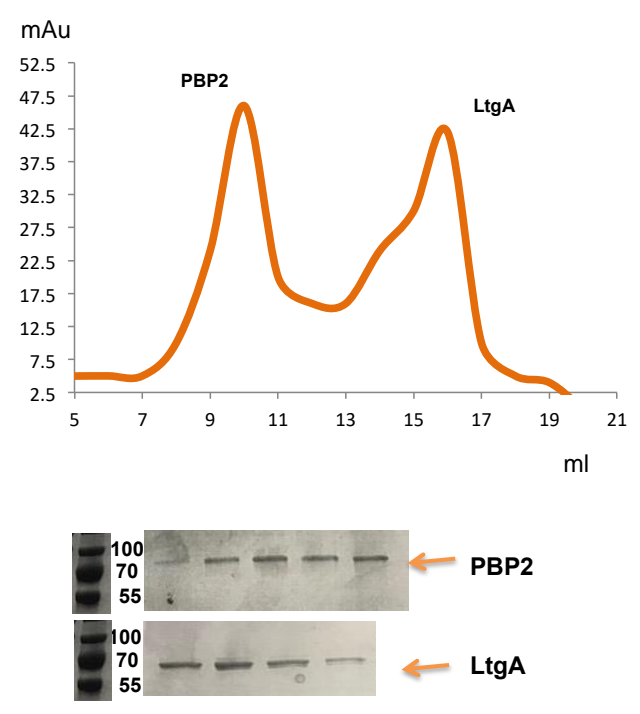

\section{Supplementary Figure 6. Gel filtration analysis of PBP2 and LtgA.}

1134 Oligomeric PBP2 and LtgA run as separate species over gel filtration. Fractions were analyzed by using SDS-PAGE. 
a)
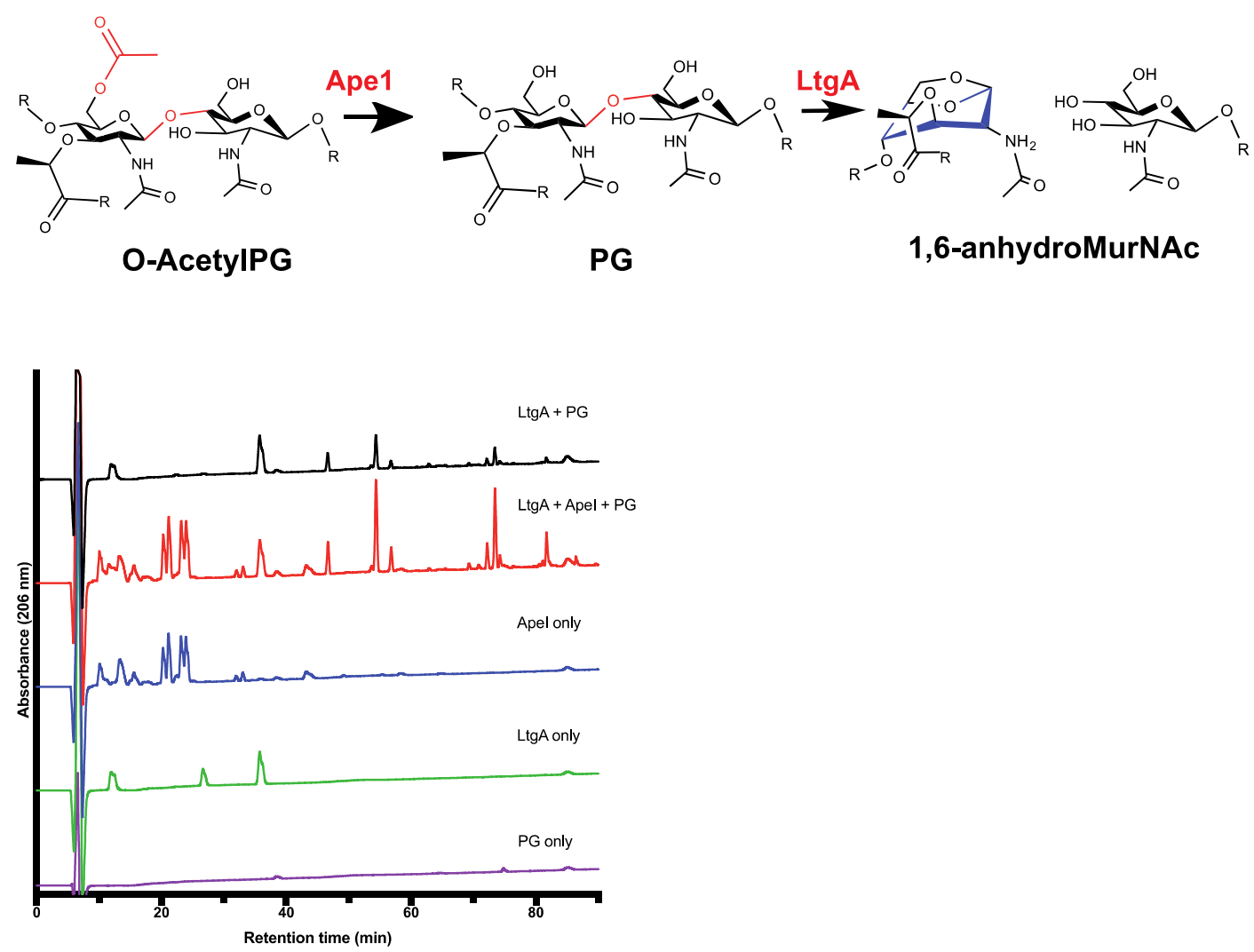

b)

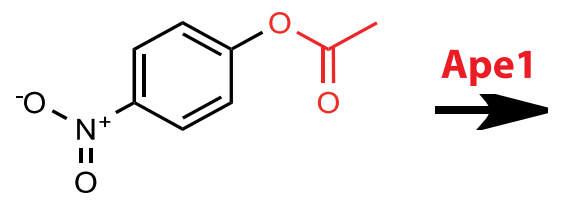<smiles>O=[N+]([O-])c1ccc(O)cc1</smiles>

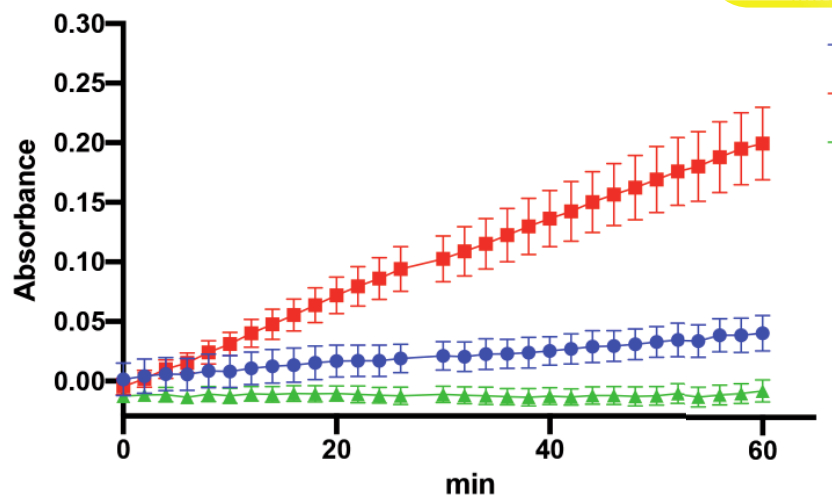

$\rightarrow$ Ape1

- LtgA-Ape1

$\rightarrow \operatorname{Ltg} A$

Supplementary Figure 7. LtgA stimulates and stabilizes the enzymatic activity of Ape1.

a) Stimulation of $\operatorname{Ltg}$ A processivity toward acetylated PG by Ape1.

b) LtgA stimulates and stabilizes Ape1 activity. Error bars shows the standard deviation of triplicates. 
bioRxiv preprint doi: https://doi org/10.1101/607697; this version posted April 12, 2019. The copyright holder for this preprint (which was not certified by peer review) is the author/funder, who has granted bioRxiv a license to display the preprint in perpetuity. It is made available under aCC-BY 4.0 International license.

a) PBP1a

Paraburkholderia/ Burkholderia

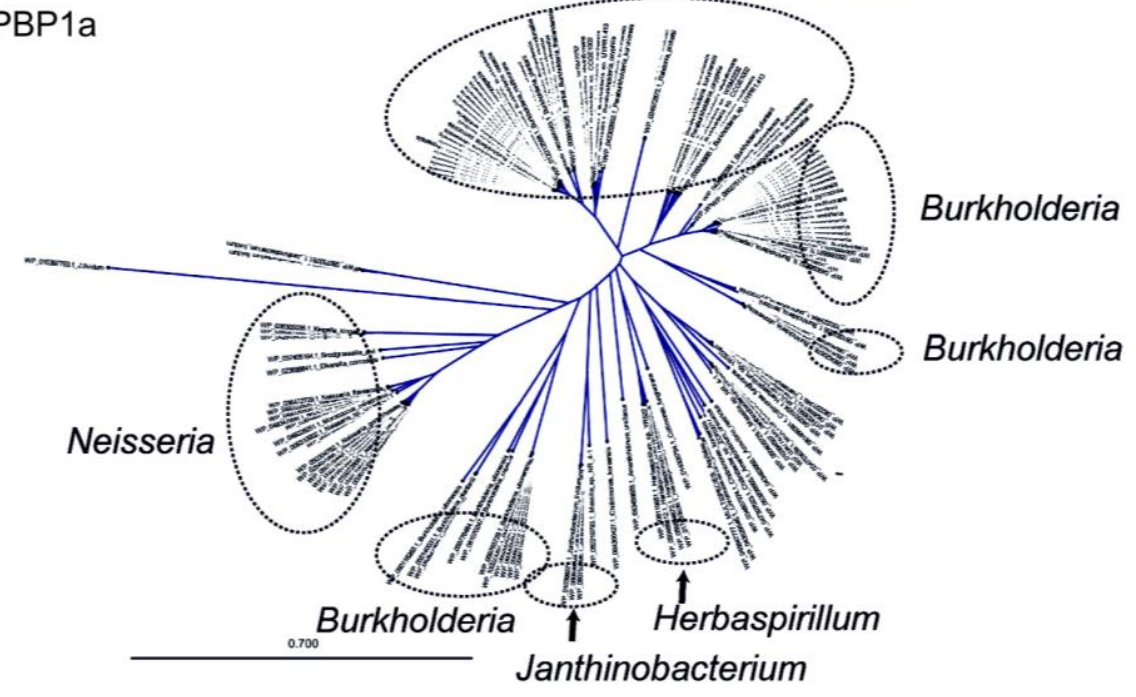

b) $\operatorname{Ltg} E$

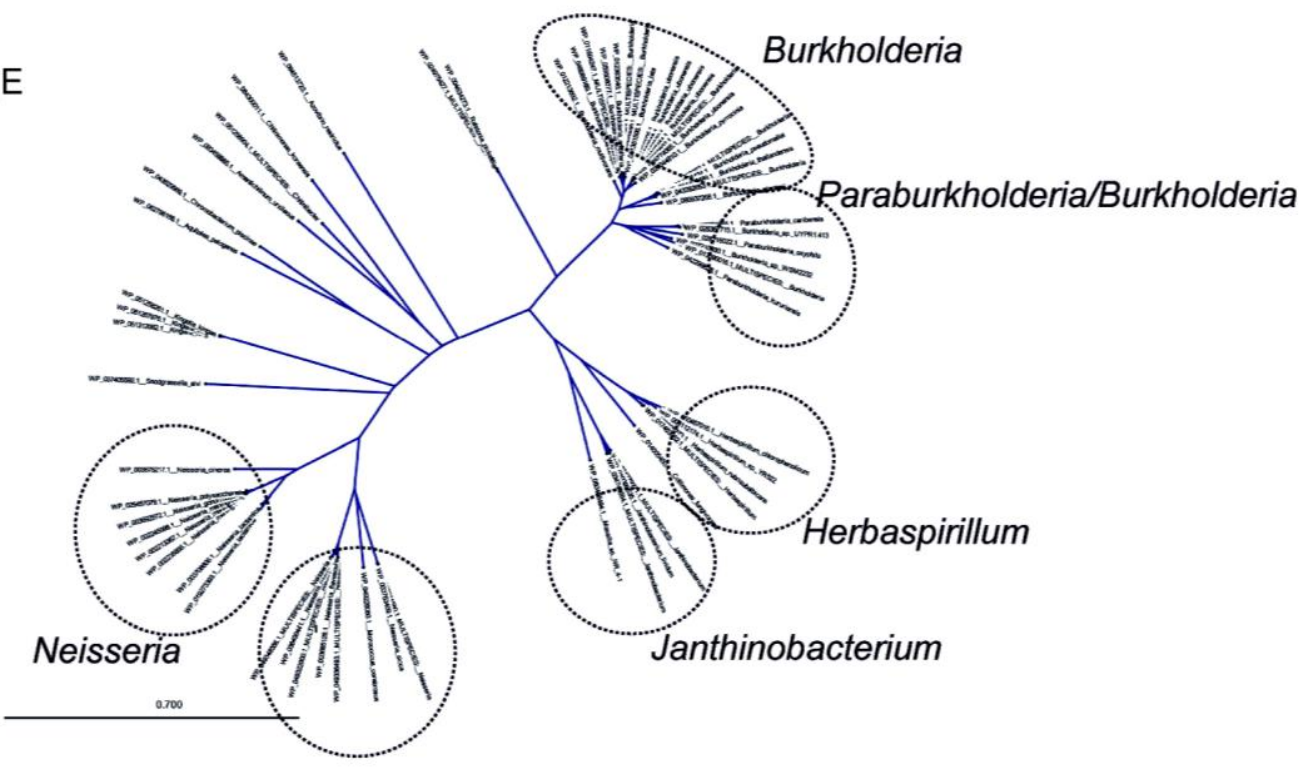


bioRxiv preprint doi: https://doi.org/10.1101/607697; this version posted April 12 2019. The copyright holder for this preprint (which was not certified by peer review) is the author/funder, who has granted bioRxiv a license to display the preprint in perpetuity. It is made available under aCC-BY 4.0 International license.

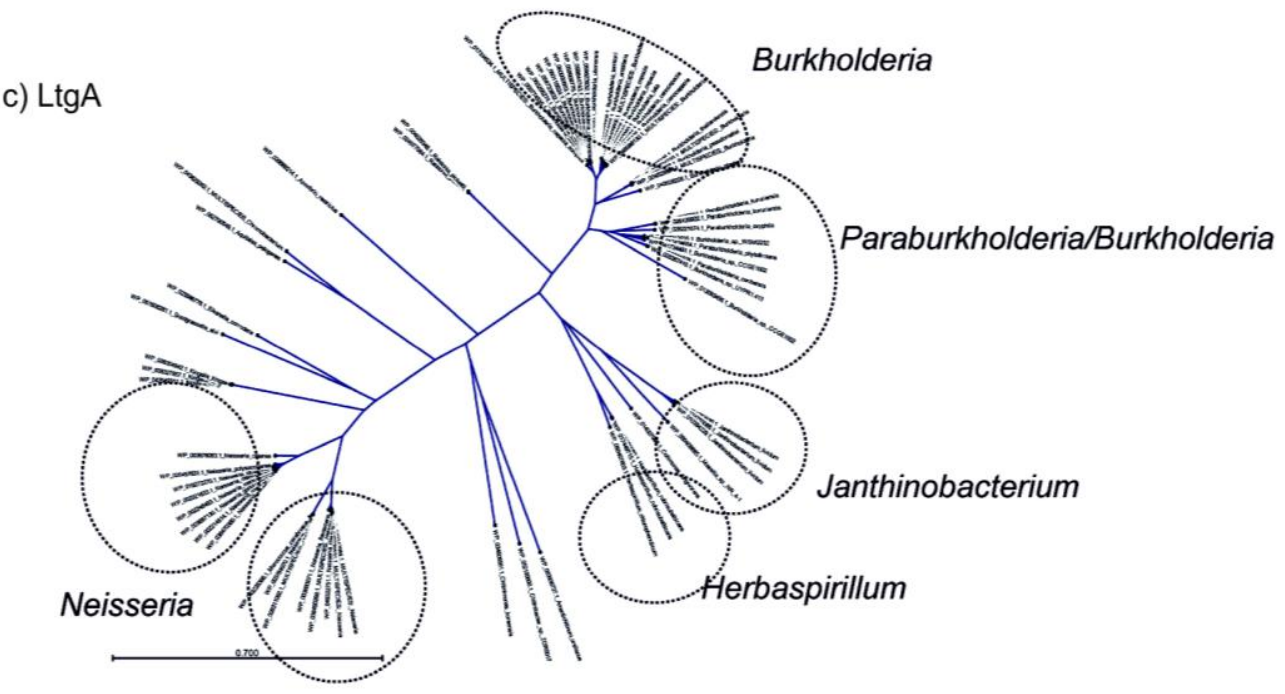

d) Ape1

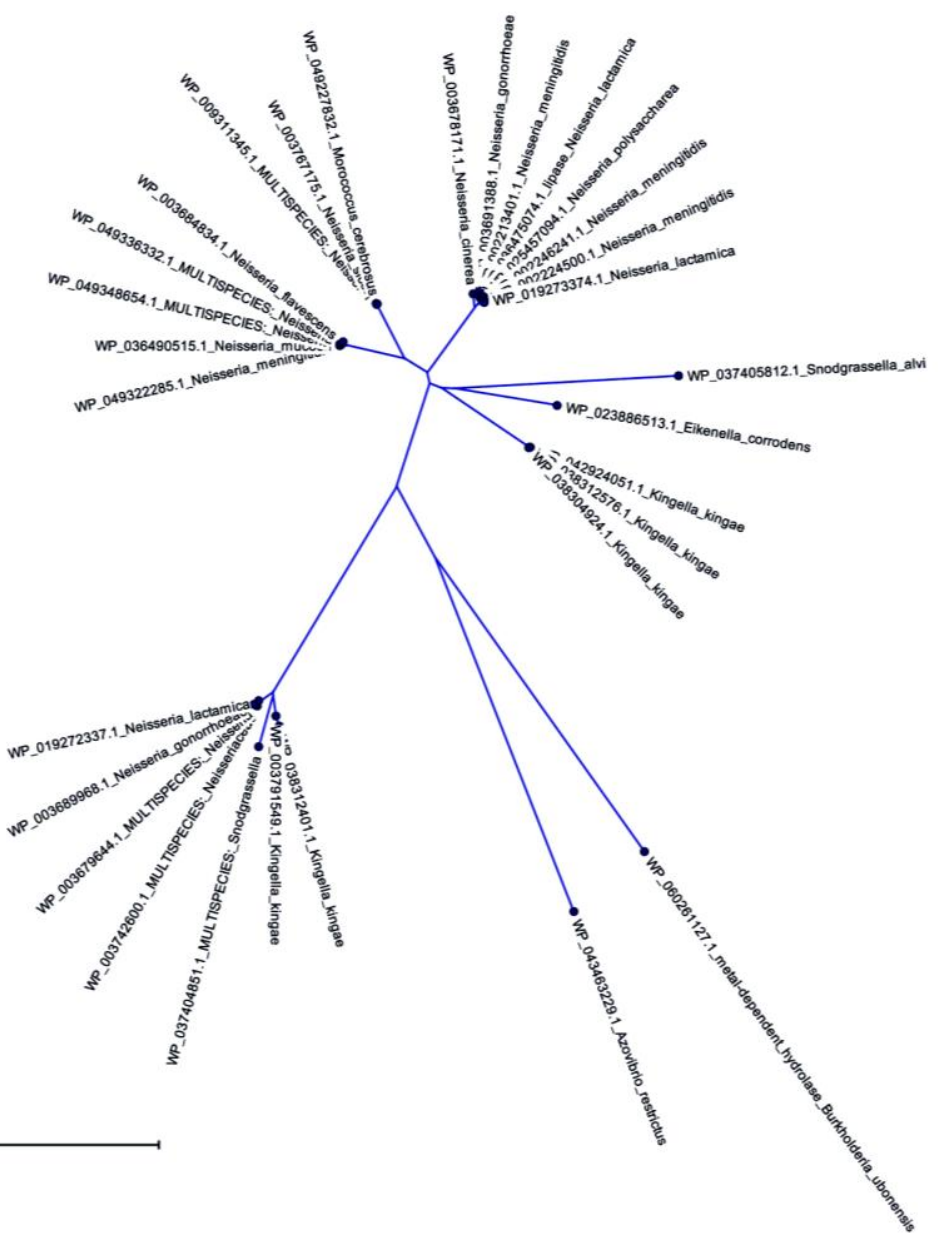




\begin{tabular}{|c|c|c|c|}
\hline Peak & $\begin{array}{c}\text { Observed } \\
\text { mass }\left(m \neq H^{*}\right)\end{array}$ & $\begin{array}{l}\text { Theoretical } \\
\text { mass }\left(\boldsymbol{m} * H^{*}\right)\end{array}$ & Structure \\
\hline 1 & 499.21 & 499.21 & GM \\
\hline 2 & 462.22 & 462.22 & 4 \\
\hline 3 & 533.26 & 533.26 & 5 \\
\hline \multirow[t]{2}{*}{4} & 699.29 & 699.29 & $\mathrm{GM} 2$ \\
\hline & 871.38 & 871.38 & GM3 \\
\hline 5 & 541.22 & 541.22 & $\mathrm{GM}^{*}$ \\
\hline \multirow[t]{2}{*}{6} & 739.33 & 739.34 & M4 \\
\hline & 942.41 & 942.42 & GM4 \\
\hline \multirow[t]{2}{*}{7} & 1013.45 & 1013.45 & GM5 \\
\hline & 913.39 & 913.39 & $\mathrm{GM}^{*} 3$ \\
\hline 8 & 905.42 & 905.42 & $4=4$ \\
\hline 9 & 984.42 & 984.43 & $\mathrm{GM}^{*} 4$ \\
\hline 10 & 1385.61 & 1385.62 & $\mathrm{GM} 4=4$ \\
\hline 11 & 851.35 & 851.35 & GanhyM3 \\
\hline 12 & 1865.80 & 1865.81 & $\mathrm{GM} 4$ - GM4 \\
\hline 13 & 1936.84 & 1936.85 & GM4 - GM5 \\
\hline \multirow[t]{2}{*}{14} & 1427.62 & 1427.63 & $\mathrm{GM}^{*} 4-4$ \\
\hline & 1907.82 & 1907.82 & $\mathrm{GM} 4=\mathrm{GM}^{*} 4$ \\
\hline \multirow[t]{2}{*}{15} & 922.39 & 922.39 & GanhyM4 \\
\hline & 1978.85 & 1978.86 & GM4 - GM5* \\
\hline 16 & 1949.83 & 1949.83 & $\mathrm{GM}^{*} 4-\mathrm{GM}^{*} 4$ \\
\hline
\end{tabular}

Supplementary Table 1. Muropeptides identified by mass spectrometry. * indicates $O$ acetylated MurNAc. Acetylated muropeptides are highlighted in pink. Where multiple

\section{Supplementary Table 2. List of Neisseria proteins identified and quantified by LC-MS/MS}

1160 after co-immunoprecipitation of $\mathbf{L t g A}$. Proteins that were identified as $\operatorname{Ltg} \mathrm{A}$ interaction partners are indicated in green (73 interaction partners were identified in the $\triangle \operatorname{ltg} A^{\operatorname{ltg} A}$ strain and 116234 interaction partners in the $\Delta \operatorname{ltg} A^{\operatorname{ltg} A \Delta 30}$ strain). The values in column $\mathrm{C}$ indicate the fold change 1163 (in $\log 2$ ) between each pair of samples. The values in column D indicate the statistical 1164 significance (-log p value). For each protein, both values are also plotted in the volcano plots in 1165 Fig. 5 (fold change values on the $\mathrm{x}$-axis and $-\log \mathrm{p}$ values on the $\mathrm{y}$-axis). See enclosed excel 1166 sheet. 
bioRxiv preprint doi: https://doi org/101101/607697; this version posted April 12 2019. The copyright holder for this preprint (which was not certified by peer review) is the author/funder, who has granted bioRxiv a license to display the preprint in perpetuity. It is made available under aCC-BY 4.0 International license.

Values in parentheses are for the outer shell.

\section{Data Collection}

Ligand added

Data collection

Wavelength $(\AA)$

Resolution range $(\AA)$

Space group

Unit-cell parameters

$a(\AA)$

$b(\AA)$

$c(\AA)$

$\sigma\left({ }^{\circ}\right), \beta\left({ }^{\circ}\right), Y\left({ }^{\circ}\right)$

\section{$\operatorname{Ltg} A$}

0.9795

49.84-1.98 (2.067-

1.995)

$P 2{ }_{1}{ }_{1} 2_{1}$

66.82

72.25

122.31

90

299848

40499

$7.4(7.4)$

$98.63(94.17)$

$16.40(1.47)$

43.22

$0.055(0.063)$

$0.1929(0.3192)$

$0.2464(0.3645)$

4661

271

563

0.007

0.96

98

0

51.00

50.80

54.60

2.09

${ }^{\dagger} R_{\text {merge }}=\Sigma_{\text {hk }} \Sigma_{\mathrm{i}}\left|l_{\mathrm{i}}(h k l)-\left\langle I_{(h k l)}\right\rangle\right| / \Sigma_{\text {hk }} \Sigma_{1} I_{(h k l)}$

${ }^{\ddagger} R_{\text {factor }}=\Sigma_{\text {hkl }}|| F_{\text {obs }}\left|-F_{\text {calc }}\right|\left|/ \Sigma_{\text {hkl }}\right| F_{\text {obs }} \mid$

${ }^{*} R_{\text {free }}$ was computed identically except that

all reflections belonged to a test set consisting of a $10 \%$ random selection of the data. 